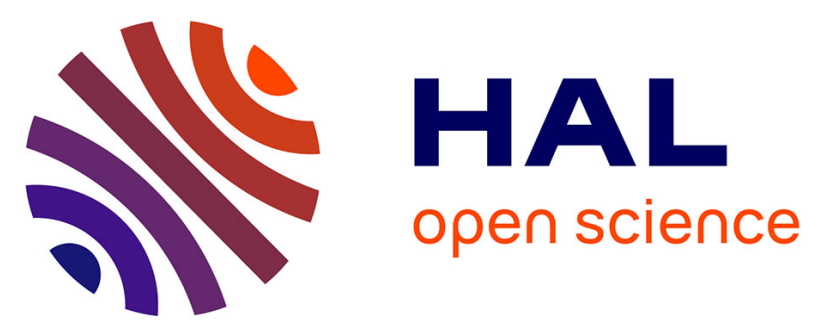

\title{
Altered expression of genes functioning in lipid homeostasis is associated with lipid deposition in NOD mouse lacrimal gland
}

Kaijin Wu, Corinne Joffre, X.L. Xiaodong Li, Michelle Macveigh-Aloni, Melinda Hom, Juliana Hwang, C.D. Chuanqing Ding, Stéphane S. Grégoire, Lionel Brétillon, Zhjiang F. Zong, et al.

\section{To cite this version:}

Kaijin Wu, Corinne Joffre, X.L. Xiaodong Li, Michelle Macveigh-Aloni, Melinda Hom, et al.. Altered expression of genes functioning in lipid homeostasis is associated with lipid deposition in NOD mouse lacrimal gland. Experimental Eye Research, 2009, 89 (3), pp.319-332. 10.1016/j.exer.2009.03.020 . hal-02664307

\section{HAL Id: hal-02664307 https://hal.inrae.fr/hal-02664307}

Submitted on 31 May 2020

HAL is a multi-disciplinary open access archive for the deposit and dissemination of scientific research documents, whether they are published or not. The documents may come from teaching and research institutions in France or abroad, or from public or private research centers.
L'archive ouverte pluridisciplinaire HAL, est destinée au dépôt et à la diffusion de documents scientifiques de niveau recherche, publiés ou non, émanant des établissements d'enseignement et de recherche français ou étrangers, des laboratoires publics ou privés. 


\title{
Altered expression of genes functioning in lipid homeostasis is associated with lipid deposition in NOD mouse lacrimal gland
}

\author{
Kaijin $\mathrm{Wu}^{\mathrm{a}}$, Corrine Joffre ${ }^{\mathrm{b}}$, Xiaodong $\mathrm{Li}^{\mathrm{a}}{ }$, Michelle MacVeigh-Aloni ${ }^{\mathrm{c}}$, Melinda Hom ${ }^{\mathrm{a}}$, Juliana Hwang ${ }^{\mathrm{a}}$, \\ Chuanqing Ding ${ }^{\mathrm{d}}$, Stephane Gregoire ${ }^{\mathrm{b}}$, Lionel Bretillon ${ }^{\mathrm{b}}$, Jiang F. Zhong ${ }^{\mathrm{e}}$, Sarah F. Hamm-Alvarez ${ }^{\mathrm{a}, *}$ \\ ${ }^{a}$ Department of Pharmacology and Pharmaceutical Sciences, University of Southern California, CA 90089, USA \\ ${ }^{\mathrm{b}}$ Eye and Nutrition Research Group, National Institute for Research on Agronomy, Dijon, Burgundy 21065, France \\ ${ }^{c}$ Center for Liver Diseases, University of Southern California, CA 90089, USA \\ ${ }^{\mathrm{d}}$ Department of Cell and Neurobiology, University of Southern California, CA 90089, USA \\ ${ }^{\mathrm{e}}$ Department of Pathology and Neurology, University of Southern California, Los Angeles, CA 90089, USA
}

\section{A R T I C L E I N F O}

\section{Article history:}

Received 5 November 2008

Accepted in revised form 24 March 2009

Available online 2 April 2009

\section{Keywords:}

NOD mouse

lacrimal gland

Sjögren's syndrome

microarray

lipid

apolipoprotein $\mathrm{F}$

apolipoprotein $\mathrm{E}$

\begin{abstract}
A B S T R A C T
Functional atrophy and accompanying lymphocytic infiltration and destruction of the lacrimal gland (LG) are characteristics of Sjögren's Syndrome (SjS). The male NOD mouse is an experimental model for the autoimmune exocrinopathy that develops in the LG of SjS patients. Acinar cells in LG of male NOD mice aged 3-4 months were previously shown to accumulate lipid droplets. In the current study, analysis of lipid components revealed that the accumulated lipids were mostly cholesteryl esters (CE). Gene expression microarray analysis followed by real-time RT-PCR revealed alterations in the expression of several genes involved in lipid homeostasis in LG of 12-week-old male NOD mice relative to matched BALB/c controls. A series of upregulated genes including apolipoprotein $\mathrm{E}$, apolipoprotein $\mathrm{F}$, hepatic lipase, phosphomevalonate kinase, ATP-binding cassette D1 and ATP-binding cassette G1 were identified. Comparison of liver mRNAs to LG mRNAs in BALB/c and NOD mice revealed that the differential expressions were LG-specific. Gene expression profiles were also characterized in LGs of female mice, younger mice and immuneincompetent NOD SCID mice. Investigation of the cellular distribution of Apo-E and Apo-F proteins suggested that these proteins normally coordinate to mediate lipid efflux from the acinar cells but that dysfunction of these processes due to missorting of Apo-F may contribute to CE deposition. Finally, the initiation and extent of lipid deposition were correlated with lymphocytic infiltration in the LG of male NOD mice. We propose that impaired lipid efflux contributes to lipid deposition, an event that may contribute to the development and/or progression of dacryoadenitis in the male NOD mouse.
\end{abstract}

(c) 2009 Elsevier Ltd. All rights reserved.

\section{Introduction}

Sjögren's syndrome $(\mathrm{SjS})^{1}$ is a chronic autoimmune disorder, characterized by lymphocytic infiltration and malfunction of the

\footnotetext{
* Corresponding author. USC School of Pharmacy, 1985 Zonal Avenue, Los Angeles CA 90033, USA. Tel.: +1 (323) 442 1445; fax: +1 (323) 4421390.

E-mail address: shalvar@usc.edu (S.F. Hamm-Alvarez).

${ }^{1}$ SjS, Sjögren's syndrome; LG, lacrimal gland(s); SG, salivary gland(s); MS, multiple sclerosis; SLE, systemic lupus erythematosus; MRI; magnetic resonance imaging; CT, computed tomography; NOD, non-obese diabetic; SCID, severe combined immune deficiency; ORO, oil red O; CE, cholesteryl ester; DIG, digoxygenin; RT, reverse transcription; PCR, polymerase chain reaction; FC, fold change; Abcd1, ATP-binding cassette, subfamily D, member 1 ; Abcg1, ATP-binding cassette, subfamily G, member 1; Apoe, gene for apo-E protein; Apo-E, apolipoprotein E; Apof, gene for apo-F protein; Apo-F, apolipoprotein F; Hprt1, gene for hypoxanthine phosphoribosyltransferase 1; Lipc, gene for hepatic lipase; LTIP, lipid transfer inhibitor protein; LTP, lipid transfer protein; Mgll, gene for monoglyceride lipase; Pmvk, gene for phosphomevalonate kinase; Sdha, gene for succinate dehydrogenase complex, subunit A. All abbreviations for mouse genes are as designated in the NCBI database with the first letter capitalized and the rest of the letters in lower case.
}

exocrine glands including the lacrimal gland (LG) and salivary gland (SG), and resulting in severe dry eyes and dry mouth that lead to compromised visual acuity and dental health (Jonsson et al., 2000; Fox, 2007). The LG is responsible for the production and regulated release of diverse proteins that provide essential ocular surface functions: proteins such as secretory immunoglobulin A (Franklin et al., 1973; Van Haeringen, 1981; Sullivan and Allansmith, 1984) and lipocalins (Ressot et al., 1998; Redl, 2000; Gasymov et al., 2005) protect the ocular surface from pathogens and damage from oxidative stress, while other proteins such as lacritin and growth factors (Klenkler et al., 2007 and references therein) sustain the integrity of the cornea. Diseases associated with impaired LG function, range from keratoconjunctivitis sicca (dry eye) to the severe autoimmune disorder, $\mathrm{SjS}$. SjS is one of the most prevalent autoimmune diseases in the United States, and is considered a significantly underdiagnosed disorder (Zoukhri, 2006). A conservative estimate for its prevalence is a million women alone in 
North America (Fox, 2000). Despite the large number of affected individuals and the quality of life issues associated with living with a chronic autoimmune disease, the etiology and pathogenesis of SjS is largely unknown. Although recent studies have implicated certain genomic loci (Aec1 and Aec2) and biological pathways in the development of autoimmune exocrinopathy in mouse models (Robinson et al., 1996, 1997; Cha et al., 2002; Nguyen et al., 2006), the genes that contribute to pathogenesis of $\mathrm{SjS}$ have not been determined, and the links between the altered biological pathways remain missing.

The non-obese diabetic (NOD) mouse is a well established and extensively studied animal model for SjS. This strain spontaneously develops lymphocytic infiltration in submandibular (sialoadenitis) and lacrimal (dacryoadenitis) glands associated with reduced secretory flow (Nguyen et al., 2000). Lymphocytic infiltration into the LG is typically detected in male mice from $\sim 6$ to 10 weeks, but develops much later in female mice, from $~ 30$ weeks (Hunger et al., 1998; Van Blokland and Versnel, 2002). The resulting dacryoadenitis is accompanied by decreased production of lacrimal fluid. The clinical manifestations of SjS in the LG are detectable in male mice by $\sim 4$ months. The NOD SCID (severe combined immune deficiency) is a Prkdc scid congenic strain of the NOD mouse. The strain lacks functional T, B and NK cells, and is free of exocrine tissue destruction. NOD SCID mice are considered a valuable model, in conjunction with the NOD strain, for elucidating the mechanisms by which molecular/ cellular events contribute to the onset and progression of autoimmune disease without interference by the direct or indirect effects of infiltrating immune cells in the affected tissues.

In previous studies, we discovered that the immune cell infiltration in 3-4 month male NOD mouse LG consistently co-existed with lipid deposition in the cytoplasm of acinar cells within LG (Ding et al., 2006). Magnetic resonance imaging (MRI) and computed tomography (CT) scanning of the SG and LG of SjS patients have suggested progressive lipid deposition is correlated with the development of inflammation and gland flow dysfunction (Izumi et al., 1997, 1998). The pathology observed in the LG of male NOD mouse is thus comparable to the changes observed in the SG and LG of SjS patients, which reflects possible changes in biochemical pathways pertinent to lipid homeostasis. In the current study we have characterized the lipids which accumulate in the LG of NOD mice and also determined what changes in the acinar cell are potentially responsible for the lipid deposition, using microarray analysis to compare gene expression profiles of LG from male NOD and BALB/c mice. Selected data from microarray were validated by real-time RT-PCR. The changes seen in genes of interest were explored in additional NOD and BALB/c mice of both genders at 4 and 12 weeks of age, as well as in NOD SCID mice. We have also begun to analyze the pathways of lipid influx and efflux in the gland, focusing on apolipoprotein $\mathrm{E}$ (Apo-E) and apolipoprotein $\mathrm{F}$ (Apo-F). Finally, to further delineate the relationship between excess lipid deposition and autoimmunity, the time course of lipid accumulation and its correlation with lymphocytic infiltration in LG were investigated. Our study suggests that the homeostatic imbalance of lipids in the LG acinar cells of male NOD mouse may be due to changes in lipid efflux from the cell.

\section{Materials and methods}

\subsection{Animals and animal procedures}

The NOD and BALB/c mouse colonies were bred in the University of Southern California Vivarium using breeding pairs purchased from Taconic (Hudson, NY) and/or Charles River Laboratories (Wilmington, MA). NOD SCID mice were purchased from Taconic. Animals were treated and sacrificed in accordance with policies approved by the University of Southern California Institutional Animal Care and Use Committee. LG or liver was removed from mice at different ages, after the animals were euthanized by intraperitoneal injection with $55 \mathrm{mg}$ of Ketaject and $14 \mathrm{mg}$ of Xylazine per $\mathrm{kg}$ of body weight followed by cervical dislocation. After removal, LG was either snap frozen and stored in liquid nitrogen for RNA preparation, immersed in chloroform : methanol (2:1) in a tightly capped glass vial at $-20{ }^{\circ} \mathrm{C}$ for lipid analysis, or fixed immediately with $4 \%$ paraformaldehyde and $4 \%$ sucrose in PBS for histology or immunofluorescence microscopy. Liver samples were snap frozen and stored in liquid nitrogen for RNA preparation.

To collect tear from mouse ocular surface, the LG in an anesthetized mouse was exposed by a small incision along an axis defined by the outer junction of the eyelid and the ear, then covered with a layer of fine cellulose mesh (Kimwipe ${ }^{\circledR}$ ) cut into a similar size as the gland. The LG was stimulated by adding the agonist carbamylcholine ( $5 \mu \mathrm{L}, 10 \mu \mathrm{M}$ ) onto the mesh on the top of the gland, and tear fluid was collected with glass capillaries at the medial canthus of the eye with care taken not to touch the cornea. Each eye was stimulated two times, in a total collection time of 10 min per eye. Mice were then euthanized as described above. The collected tear fluid was transferred from the capillaries to an eppendorf tube containing protease inhibitors, measured for precise volume, mixed with SDS sample buffer, pooled when necessary, and heated at $92{ }^{\circ} \mathrm{C}$ for $5 \mathrm{~min}$.

To collect lacrimal fluid from rabbits, female New Zealand rabbits weighted $\geq 4 \mathrm{~kg}$ were anesthetized by intramuscular injection of Ketaject and Xylazine at $25 \mathrm{mg}$ and $5 \mathrm{mg} / \mathrm{kg}$ body weight respectively. In the anesthetized rabbit, one end of a $4-\mathrm{cm}$ long silicon tubing cannula was inserted by hand into the duct lumen from the open end located at the corner of the eye. Lacrimal fluid was collected through the other end of the tubing into a glass test tube on ice following stimulation with $1 \mathrm{~mL}$ of pilocarpine at $1.2 \mathrm{mg} / \mathrm{mL}$ saline, by injection through the marginal ear vein. The stimulation was repeated 3 times in each rabbit and the interval between each time was $10 \mathrm{~min}$. The collected lacrimal fluid was stored at $-80{ }^{\circ} \mathrm{C}$ until lipid extraction. The rabbits were then euthanized by intravenous injection with sodium pentobarbital (Euthasol) at $120 \mathrm{mg} / \mathrm{kg}$ body weight after the collection.

\subsection{Reagents and supplies}

The VersaGene RNA Tissue Kit, originally from Gentra Systems, was later purchased from Thermo Fisher Scientific, Inc. (Fair Lawn, NJ) under the name 5 PRIME PerfectPure RNA Tissue Kit (FP2302410). All materials and reagents for microarray were purchased from Applied Biosystems (ABI, Foster City, CA) through the Vanderbilt Microarray Shared Resources (VMSR, Vanderbilt University, Nashville, TN). All the following materials and reagents for RT and real-time PCR were purchased directly from ABI: the high capacity cDNA RT kit (4368814), TaqMan ${ }^{\circledR}$ universal PCR master mix for real-time PCR (4324018), MicroAmp ${ }^{\mathrm{TM}}$ optical 384well reaction plates (4309849) and MicroAmp ${ }^{\mathrm{TM}}$ optical adhesive films (4311971), and TaqMan ${ }^{\circledR}$ gene expression assays (groups 1 and 2). Group 1 probes include those for the genes of interest including Abcd1 (Mm00431749_m1), Abcg1 (Mm00437390_m1), Apoe (Mm00437573_m1), Apof (Mm00506066_g1), Lipc (Mm00433975_m1), Mgll (Mm00449274_m1) and Pvmk (Mm00503429_m1). Group 2 probes include those for genes serving as internal controls including Hprt1 (Mm00446968_m1) and Sdha (Mm01352357_m1). Mm followed by 8 digits represents the company assay ID for a TaqMan ${ }^{\circledR}$ gene expression assay corresponding to a specific mRNA locus of a gene. Goat anti-mouse Apo-E polyclonal antibody (sc-6384) was purchased from Santa Cruz Biotechnology, Inc. (Santa Cruz, CA); rat anti-Lamp2 monoclonal antibody (ab13524) purchased from Abcam 
(Cambridge, MA). Glyco ${ }^{\circledR}$-Sialidase A $^{\mathrm{TM}} /$ NANase III (GK80040) and Glyko $^{\circledR}-\mathrm{O}-$-Glycanase ${ }^{\circledR}$ (GK80090) were purchased from PROzyme GLYKO (San Leandro, CA). Oil Red O (ORO) was purchased from EMS (Hatfield, PA).

\subsection{Preparation of total RNA}

The preparation was conducted using the VersaGene RNA Tissue Kit or 5 PRIME PerfectPure RNA Tissue Kit at room temperature. A pair of LG or a small piece of liver was taken out from liquid nitrogen, and quickly homogenized in lysis buffer on ice using a Brinkman Polytron tissue homogenizer. The lysate was filtered through a Pre-Clear spin column by centrifugation. The clarified lysate was run through a purification column by centrifugation. The RNAbound membrane was treated with DNase I. The RNA was eluted into a collection tube from the column with elution buffer. Three LG RNA samples were pooled from 3 mice in equal amounts for microarray analysis and real-time RT-PCR. The liver RNA samples from 12-weekold mice were also pooled similarly to the LG RNA samples above for real-time RT-PCR. Each RNA sample was prepared for real-time RTPCR from 3 to 4 pairs of pooled LGs when 4 -week-old mice were used. All the purified RNA samples were stored at $-80^{\circ} \mathrm{C}$.

\subsection{Gene expression microarray analysis}

Triplicates of ABI Mouse Genome Survey Microarray, AB1700 version 1.0.1 (4382672) were used for each group of mice. Each chip was printed with about 33,000 60-mer oligos as probes, representing a complete annotated and curated set of approximately 32,000 mouse genes from the public and Celera databases. The microarray analysis and the sequential data normalization were conducted by VMSR. Before microarray, the purity and integrity of RNAs were confirmed by measurement on an Agilent Bioanalyzer according to the manufacturer's manual. In brief, $1 \mu \mathrm{g}$ of total RNA (containing about $30 \mathrm{ng}$ mRNA) was used to generate double-stranded cDNA using ABI NanoAmp ${ }^{\mathrm{TM}}$ RT-IVT labeling kit (4365715) according to manufacturer's protocol. The entire cDNA product was used in an IVT reaction to generate digoxigenin (DIG)-labeled cRNA. The cRNA was purified using a kit column and assessed for quality on an Agilent Bioanalyzer. All hybridization reagents, hybridization controls, wash reagents, and chemiluminescent reagents were provided in the ABI Chemiluminescence Detection Kit (4342142), and the manufacturer's protocol was followed in the subsequent hybridization procedure. Briefly, the arrays were pre-hybridized with a $1 \mathrm{~mL}$ of pre-hybridization mixture for $60 \mathrm{~min}$ with agitation at $100 \mathrm{RPM}$ and $55^{\circ} \mathrm{C}$ in a hybridization oven. $0.5 \mathrm{~mL}$ of fragmented DIG-labeled targets mixed with hybridization controls was added to the pre-hybridization solution. The arrays were continually incubated at $55{ }^{\circ} \mathrm{C}$ and agitated at 100 RPM for $16 \mathrm{~h}$. The arrays were washed and incubated with anti-DIG-AP antibody for 20 min. Following antibody washes, the arrays were incubated with Chemiluminescence Enhancing Solution for $20 \mathrm{~min}$. Substrate for the chemiluminescence reaction was added to each array individually one array at a time. The array was immediately imaged on the 1700 Chemiluminescent Microarray Analyzer. The images were assessed for QA/QC and a primary analysis was completed by the AB1700 Expression Array System Software (v 1.1.1). The raw data were normalized using the ABI quantile-based method and filtered according to the average scores of flags with the analyzer and associated software.

\subsection{Reverse transcription (RT) and real-time polymerase chain reaction $(P C R)$}

Two reaction steps were carried out with $\mathrm{ABI}$ reaction kits and reagents according to the manufacturer's protocols. Briefly, RT reaction was conducted with $1 \mu \mathrm{g}$ of total RNA per $10 \mu \mathrm{L}$ of reaction volume at $25^{\circ} \mathrm{C}$ for $10 \mathrm{~min}$ then $37^{\circ} \mathrm{C}$ for $2 \mathrm{~h}$, and terminated at $85^{\circ} \mathrm{C}$ for $5 \mathrm{~s}$, using the high capacity cDNA RT kit. Real-time PCR was conducted using an ABI 7900HT Fast Real-Time PCR System. $1 \mu \mathrm{L}$ of RT product (diluted with $3.5 \mu \mathrm{L}$ of nuclease-free $\mathrm{H}_{2} \mathrm{O}$ ), $0.5 \mu \mathrm{L}$ of the TaqMan ${ }^{\circledR}$ Assay Mixture and $5 \mu \mathrm{L}$ of Universal Master Mix were used in each reaction in a total volume of $10 \mu \mathrm{L}$. Triplicates of reaction were run for each assay. The samples were preheated at $95^{\circ} \mathrm{C}$ for $10 \mathrm{~min}$, followed by 40 cycles of $95^{\circ} \mathrm{C}$ for $15 \mathrm{~s}$ and $60^{\circ} \mathrm{C}$ for $1 \mathrm{~min}$. The reactions with the TaqMan ${ }^{\circledR}$ assay for the house-keeping genes, Hprt1 (hypoxanthine phosphoribosyltransferase 1) or Sdha (succinate dehydrogenase complex, subunit A), were run as internal controls. The recorded data were analyzed using the $\Delta \Delta \mathrm{Ct}$ study calculating function of the ABI software SDS 2.1. The fold change (FC) for a specific mRNA was obtained by calculations using the equations $\Delta \mathrm{Ct}=\mathrm{Ct}$ (studied mRNA) $-\mathrm{Ct}$ (house-keeping gene mRNA), $\Delta \mathrm{Ct}(\mathrm{NOD})-\Delta \mathrm{Ct}(\mathrm{BALB} / \mathrm{c})=\Delta \Delta \mathrm{Ct}$, and FC (NOD/BALB/ c) $=2^{\Delta \Delta C t}$.

\subsection{Generation and characterization of Apo-F antibody}

Rabbit anti-mouse Apo-F polyclonal antiserum was customproduced and purified using Protein A affinity column by Antibodies Incorporated (Davis, CA). The antigen for immunization was produced as a His-tagged full-length protein (without the signal peptide) in E. coli and purified by affinity chromatography. The resulting antibodies were tested by Western blotting, and shown to react with purified recombinant Apo-F protein.

\subsection{Confocal fluorescence microscopy}

Cryosections processed as described for histology and ORO staining were also used for immunofluorescence staining. For detection of Apo-E protein, sections were permeabilized with $0.1 \%$ Triton X-100 for $5 \mathrm{~min}$, then 1\% SDS for $5 \mathrm{~min}$. For detection of Apo-F and Lamp2, sections were permeabilized with $0.5 \%$ saponin for 5-10 min. Sections were then blocked with $1 \%$ BSA in PBS for at least $30 \mathrm{~min}$. The slides were incubated with diluted primary antibody in $1 \%$ BSA on the top of the tissue section at $37^{\circ} \mathrm{C}$ for $1 \mathrm{~h}$ in a moisturized chamber. Sequentially diluted fluorophore-labeled secondary antibodies in 1\% BSA and fluorophore-labeled phalloidin (where appropriate) were applied and slides were incubated in the moisturized chamber at $37^{\circ} \mathrm{C}$ for $1 \mathrm{~h}$. Finally, slides were incubated with DAPI in PBS for 5 min, rinsed with water and mounted with water soluble anti-fade mounting medium (Invitrogen, Carlsbad, CA) under a cover slip. During the whole procedure, slides were washed with PBS 2-3 times between the treatments. Samples were imaged with a Zeiss LSM 510 Meta NLO confocal/multiphoton imaging system.

\subsection{Deglycosylation of tear proteins}

Freshly collected tears were pooled and divided into equal volume of $2 \mu \mathrm{L}$ for each reaction. One aliquot of the tear fluid was stored on ice. The other three aliquots were incubated at $37^{\circ} \mathrm{C}$ for $1 \mathrm{~h}$ in a total volume of $20 \mu \mathrm{L}$ containing reaction buffer only, $10 \mathrm{mU}$ of Sialidase A, or $5 \mathrm{mU}$ of Sialidase A and $2.5 \mathrm{mU}$ of O-Glycanase. The samples were mixed with SDS-PAGE sample buffer at the end of the reaction and incubated at $95^{\circ} \mathrm{C}$ for 5 min before loading onto the gel.

\subsection{Western blotting with LG tissue lysate or tear fluid}

Pooled LGs removed from 2 to 3 mice freshly or stored at $-80^{\circ} \mathrm{C}$ were homogenized with a motor-driven homogenizer in RIPA 
buffer (150 mM NaCl, $50 \mathrm{mM}$ Tris-Cl, $0.5 \%$ sodium deoxycholate, $0.5 \mathrm{mM}$ EDTA, $0.1 \%$ TX-100, 1\% NP-40) containing protease inhibitors in a tissue : buffer ratio of $1: 5(\mathrm{w} / \mathrm{v})$. The resulting homogenate was clarified by centrifugation at $10,000 \mathrm{rpm}$ at $4{ }^{\circ} \mathrm{C}$ for $10 \mathrm{~min}$. The supernatant was collected and stored at $-80{ }^{\circ} \mathrm{C}$. An aliquot of the supernatant was mixed with sample buffer and heated at $92{ }^{\circ} \mathrm{C}$ for 5 min for the subsequent analysis.

Tissue lysate containing $100 \mu \mathrm{g}$ of total proteins or $2 \mu \mathrm{L}$ of tear fluid was loaded in each well and resolved by SDS PAGE. Proteins were transferred from the gel to nitrocellulose membranes and blotted with anti-Apo-F antibody at 1:500 dilution with blocking buffer, for $1 \mathrm{~h}$ then with IRDye 800-labeled goat anti-rabbit IgG. The membranes were scanned using an LI-COR Odyssey Infrared Imaging System.

To test the specificity of the antibody-antigen interaction, $5 \mu \mathrm{L}$ of protein A-purified anti-Apo-F antibody (34 $\mu$ g of total IgG) was incubated in blocking buffer with $1.5 \mu \mathrm{g}$ of purified recombinant His-tagged Apo-F protein in a total volume of $40 \mu \mathrm{l}$, rocked at $4{ }^{\circ} \mathrm{C}$ for $1 \mathrm{~h}$, then diluted to $5 \mathrm{~mL}$ with blocking buffer. The resulting membrane containing the resolved proteins transferred from SDS-PAGE was cut into slices. Each slice of the membrane was blotted with $5 \mathrm{~mL}$ of the diluted anti-Apo-F antibody above for $1 \mathrm{~h}$, then with IRDye 800-labeled goat anti-rabbit IgG. Another duplicate slice from the same membrane was blotted as control with the same antibody pre-incubated at $4{ }^{\circ} \mathrm{C}$ for $1 \mathrm{~h}$ without the recombinant protein.

\subsection{Classification and quantification of total lipids}

Total lipids were extracted according to the procedure derived from the method by Folch and colleagues (Folch et al., 1957). Each pair of LG was stored in $4 \mathrm{~mL}$ of the Folch mixture (chloroform : methanol, 2:1, v/v) in a screw cap sealed glass vial at $-20{ }^{\circ} \mathrm{C}$ immediately after removal from mouse until extraction. The glands were ground in the vial with a motor-driven homogenizer. Then the homogenate was transferred into a $30 \mathrm{~mL}$ glass centrifuge tube. The vial was rinsed with $2 \mathrm{~mL}$ of chloroform : methanol $(2: 1, \mathrm{v} / \mathrm{v})$ and the wash added to the centrifuge tube. After $1 \mathrm{~mL}$ of $\mathrm{NaCl}$ at $0.73 \%(\mathrm{w} / \mathrm{v}$ ) was added into the tube, the homogenate was mixed on a vortex mixer for $1 \mathrm{~min}$, then centrifuged at $3000 \mathrm{rpm}$ for $3 \mathrm{~min}$. The inferior chloroform phase containing the total lipids was recovered with a Pasteur pipette. The extract was dried under $\mathrm{N}_{2}$ flow in a heat block at $40^{\circ} \mathrm{C}$. The dried lipids were suspended in $1 \mathrm{~mL}$ of chloroform. The distribution of the lipids into phospholipids, triacylglycerols, diacylglycerols, free fatty acids, cholesterol and cholesteryl esters (CE) was determined using a combination of thin layer chromatography on silica gel-coated quartz rods and flame ionization detection (Iatroscan ${ }^{\circledR}$ system, Iatron, Tokyo, Japan) according to the technique of Ackman (Ackman, 1981). The values obtained for each compound were corrected according to their response factor by using specific calibration curves according to previously published methods (Sébédio and Juaneda, 1991). Rabbit tear CE was similarly extracted and quantified to the described above.

\subsection{Measurement of mouse plasma cholesterol}

The plasma samples were pooled from 2 to 3 mice within in each group to increase the sample volume. Several pooled samples from each group of mice were analyzed for HDL-, LDL-, VLDL- and total cholesterol. The measurements were conducted enzymatically on an automated Cobas Mira analyzer (Roche) following the standardized procedures of the National Centers for Disease Control and Prevention: Lipid Research Clinics Program. All reagents for enzymatic reactions, cholesterol standards, and HDL/LDL cholesterol calibrators utilized were purchased from Roche (Basel, Switzerland).

\subsection{Histology and ORO staining}

After removal, LG was soaked in PBS containing 4\% paraformaldehyde and $4 \%$ sucrose at room temperature for $2-3 \mathrm{~h}$. The gland was transferred to PBS containing 30\% sucrose overnight. The gland was embedded into O.C.T. and snap frozen in liquid nitrogen. The blocks were stored at $-80{ }^{\circ} \mathrm{C}$ prior to tissue sectioning. The blocks were sectioned with a Microm cryostat (Heidelberg, Germany) into 5 micron thick sections. Sections on the slides were rinsed with distilled water, and then stained in 6 parts of ORO stock solution and 4 parts of distilled water for $10 \mathrm{~min}$ followed by a rapid $70 \%$ ethanol rinse to minimize background. The slides were washed well with distilled water, counterstained in Harris hematoxylin for $30 \mathrm{~s}$, rinsed again, and incubated briefly in $0.05 \%$ lithium carbonate. The slides were then washed thoroughly and mounted in aqueous mounting medium.

\subsection{Quantification of lipid deposition in mouse $L G$ with ORO-stained sections}

LG sections stained with ORO were photographed at 100x or $200 \times$ magnification with software QCapture 5.1 using a Nikon ECLIPSE 80i light microscope. The images were analyzed using Meta Imaging Series 6.1 in MetaMorph by which the ORO-stained area visualized in red was distinguished from the other LG area visualized in blue (hematoxylin) and the stain-free non-gland area. For this analysis, LGs from three male NOD mice of each age group were analyzed with 3-6 images analyzed from each LG except for the 6-week-old group. 11 pairs of LG were analyzed at 6 weeks of age to gain a better understanding of the apparent unsynchronized appearance of focus formation by infiltrating immune cells. In these samples, 3-6 images were also analyzed from each mouse. At 100x or $200 \times$ magnification, the whole cross sectional area of the LG could be included in the analyzed images from the mice at 4, 5, or 6 weeks of age. Analyzed areas could either be a whole image, or a partial image defined by the line tool such that no redundant areas were picked up when overlapped images were processed. The size of LG from NOD mice increase rapidly from 8 weeks of age, and at 12 weeks may be up to $3 \times$ times as big as at 6 weeks. The whole cross sectional area was not covered for every gland sample in these mice. However, the lipid droplets were distributed in the acinar cells across the whole gland areas evenly as observed by microscopy at 8 and 12 weeks of age. The results from the quantification therefore remain representative, although the images analyzed may not cover the whole area of the LG in these cases. The percentage of lipid droplets occupying the LG in each mouse was approximated by dividing the total pixels of ORO-positive area in 3-6 randomly selected images with the total pixels of LG area from the same images then multiplying by $100 \%$. The final result was obtained from averaging the individual results from the animals in each age group.

\section{Results}

\subsection{Classification of accumulated lipids in LG from male NOD mice}

In earlier studies, lipid droplets were detected in the LG of 4-month-old NOD male mice (Ding et al., 2006). The lipid profiles of LG from 12-week-old male BALB/c and NOD mice were characterized by thin layer chromatography on silica gel-coated quartz rods and flame ionization detection. Before the analysis, the weights of LG from male NOD $(n=8)$ and BALB/c $(n=9)$ mice for lipid characterization were measured. LGs were significantly heavier in NOD mice than BALB/c mice (Fig. 1A and 1B). The lipid characterization results revealed that the $L G$ from NOD mice contained more lipids than the LG from BALB/c mice (Fig. 1C and 1D). CE was the major 
A
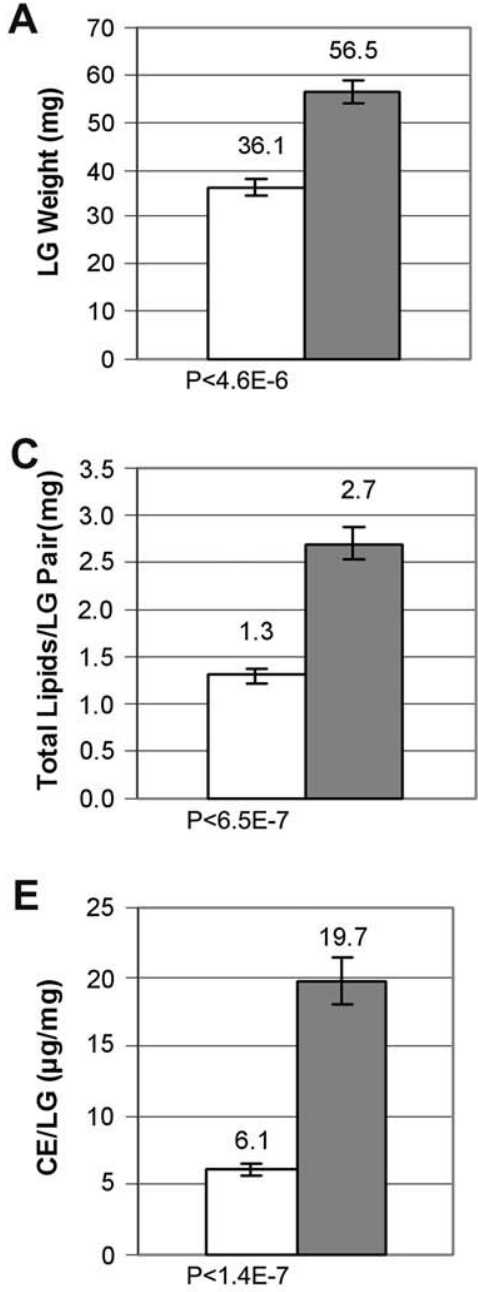

B

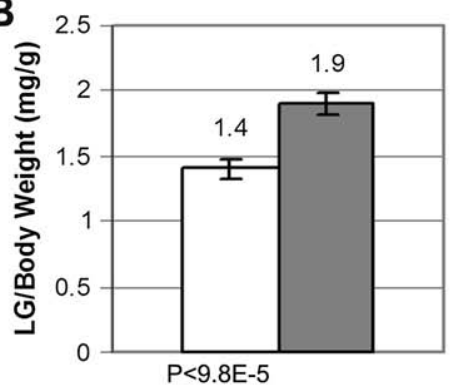

D

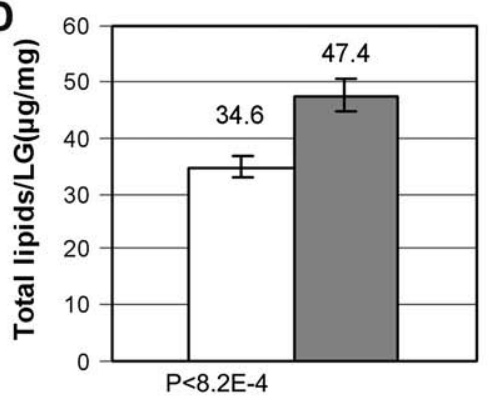

$\mathbf{F}$

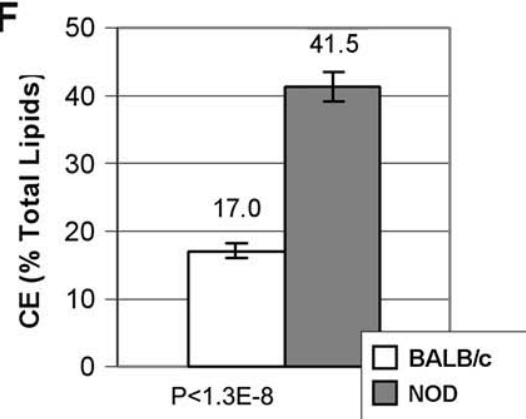

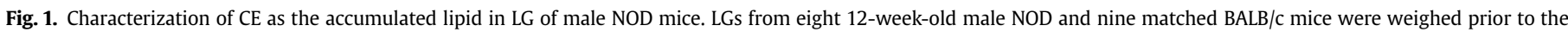

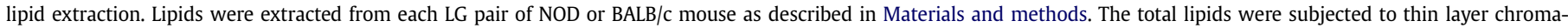

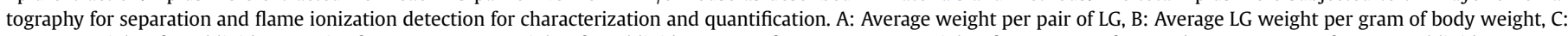

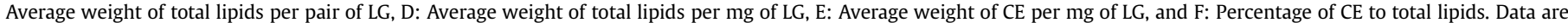
presented as Mean \pm SEM. $P$ values of statistical analysis by Student $t$-test are listed at the bottom of panels A-F.

accumulated lipid in the LG from NOD mice (Fig. 1E), while other lipid types did not display remarkable differences between the two strains (data not shown). The percentage of CE as a fraction of the total lipids was increased by $\sim 3$-fold in NOD mouse LG relative to BALB/c mouse LG (Fig. 1F). Differences were all statistically significant $(P<0.001$ by Student's $t$-test $)$.

\subsection{Homeostatic imbalance of lipids characterized in male NOD mouse $L G$ by genome survey microarray and real-time RT-PCR}

To establish how the expression profiles of lipid genes were changed, corresponding to the imbalanced lipid homeostasis, a high-density genome survey microarray analysis was performed with total RNA pools from LGs of NOD and BALB/c male mice at 12 weeks of age. The results highlight noticeable changes in expression profiles of several groups of genes involved in lipid metabolism or transport in the LG of NOD mice as summarized in Table 1.

Most apolipoproteins are predominantly produced in liver and intestine. They are known to function in regulation of intravascular metabolism of lipoproteins and their ultimate tissue uptake. They thus play an important role in systemic lipid homeostasis. However, there have been few reports about their functions in LG. Detected by microarray, apolipoprotein A II (Apoa2), apolipoprotein A IV (Apoa4), apolipoprotein C I (Apoc1), Apolipoprotein D (Apod), Apoe and Apof genes were expressed in LG. Among the expressed apolipoproteins in LG, mRNAs of Apoe and Apof in NOD mice were 2.13-fold and 33.33-fold greater, respectively, than in BALB/c mice (Table 1).

Table 1

Differentially expressed genes implicated in homeostatic imbalance of lipids in LG of 12 week NOD mice characterized by microarray analysis.

\begin{tabular}{llcll}
\hline Gene & NCBI Accession & FC & $P$ Value & Change in NOD \\
\hline Abcd1 & NM_007435 & 2.08 & 0.0217 & increase \\
Abcg1 & NM_009593 & 6.94 & 0.0008 & increase \\
Apoe & NM_009696 & 2.13 & $2.7 \mathrm{E}-5$ & increase \\
Apof & NM_133997 & 33.33 & 0.0009 & increase \\
Lipc & NM_008280 & 4.17 & 0.0147 & increase \\
Mgll & NM_011844 & 0.35 & $4.2 \mathrm{E}-6$ & decrease \\
Pmvk & NM_026784 & 6.29 & 0.0005 & increase \\
\hline
\end{tabular}

FC: fold change, obtained by comparing the signal intensities of hybridization reaction on the chips with-labeled cRNA from LGs of either 12-week-old NOD or $\mathrm{BALB} / \mathrm{c}$ mice (NOD/BALB/c) after normalization. The signal intensity of each reaction is the average of hybridization reactions conducted in triplicate. Abcd1: ATP-binding cassette, subfamily D, member 1; Abcg1: ATP-binding cassette, subfamily G, member 1; Apoe: apolipoprotein E; Apof: apolipoprotein F; Lipc: hepatic lipase; Mgll: monoglyceride lipase; Pmvk: Phosphomevalonate kinase. 
The ATP-binding cassette $(A B C)$ superfamily is a group of transporters including some lipid transporters. The mRNAs of several ABC lipid-transporting members including Abca1, Abcd1, Abcg1, and Abcg 4 were detected in the LG inspected by microarray analysis. Three of the four gene products have been demonstrated to play pivotal roles in lipid homeostasis, and their deficiencies cause severe diseases in human (ABCA1 and ABCD1) (Cartier et al., 1993; Brooks-Wilson et al., 1999; Young and Fielding, 1999; Oram, 2000) or animal models (Abcg1) (Kennedy et al., 2005; Baldan et al., 2006). Among these, Abcd1 and Abcg1 were upregulated to 2.08and 6.94-fold in 12-week old male NOD mouse LG relative to BALB/ c controls (Table 1 ).

Another group of genes characterized were the lipases, which function in hydrolysis and transport of esters. The mouse LG expressed only three lipases at a detectable level, carboxyl ester lipase (Cel), monoglyceride lipase (Mgll), and hepatic lipase (Lipc) according to microarray analysis. Among these genes, Lipc was upregulated 4.17-fold and Mgll was downregulated 0.35 -fold in NOD mouse LG (Table 1 ).

The expression of enzymes involved in cholesterol biosynthesis was also of interest since alteration in this pathway is among the possibilities which could result in excess CE deposition within the LG of male NOD mice. The full spectrum of enzymes in cholesterol biosynthesis is expressed in LG according to the microarray analysis, indicating the acinar cells actively produce cholesterol. However, only one of the non rate-limiting enzymes in cholesterol biosynthesis was significantly changed: the abundance of phosphomevalonate kinase (Pmvk) mRNA was 6.29-fold higher in NOD mice than in matched BALB/c mice (Table 1 ).

\subsection{Validation of gene expression profiles}

To validate the results of microarray analysis, the expression profiles of the genes noted above were confirmed by real-time RTPCR with total RNAs prepared from LGs of male mice at 12 weeks of age. Furthermore, to elucidate if the differential expressions of these genes were strain-specific, gender-specific, age-dependent or inflammation-related, the differentially expressed genes identified were further compared across additional subjects by the same method. The results are presented below.

\subsubsection{Comparison of gene expression in $L G$ between gender- and age-matched NOD and BALB/C mice}

The results of these comparisons are summarized in Table 2. The increased expressions of Apof, Lipc and Pmvk genes were strainspecific: the mRNA levels of the genes were higher in both NOD groups (12-week and 4-week) than in matched BALB/c controls at

\section{Table 2}

Comparison of gene expressions in LG from gender- and age-matched NOD and $\mathrm{BALB} / \mathrm{c}$ mice by real-time RT-PCR.

\begin{tabular}{lllll}
\hline Gene & FC NOD(M)/ & FC NOD(M)/ & FC NOD(F)/ & FC NOD(F)/ \\
& BALB(M)(12 wks) & BALB(M)(4 wks) & BALB(F)(12 wks) & BALB(F)(4 wks) \\
\hline Abcd1 & $\mathbf{2 . 1 8}$ & 0.64 & 1.05 & 0.88 \\
Abcg1 & $\mathbf{5 . 2 0}$ & 1.43 & 1.88 & 1.34 \\
Apoe & $\mathbf{2 . 1 1}$ & 1.41 & 1.01 & 1.17 \\
Apof & $\mathbf{5 3 . 7 5}$ & $\mathbf{5 1 . 4 6}$ & $\mathbf{5 . 2 4}$ & $\mathbf{4 . 5 6}$ \\
& & & & \\
Lipc & $\mathbf{4 . 0 0}$ & $\mathbf{2 . 5 0}$ & $\mathbf{2 . 8 9}$ & $\mathbf{5 . 5 0}$ \\
Mgll & 0.33 & 0.35 & 0.19 & 0.34 \\
Pmvk & $\mathbf{6 . 1 4}$ & $\mathbf{1 1 . 1 0}$ & $\mathbf{9 . 0 3}$ & $\mathbf{3 7 . 3 9}$ \\
\hline
\end{tabular}

FC: fold change, obtained by calculation as described in Materials and methods. BALB: BALB/c. M: male. F: female. All fold changes equal to or greater than 2.00 are in bold. All fold changes equal to or smaller than 0.5 are in italics. The genes reportedly involved in lipid transport are listed in the top row and genes involved in lipid metabolism in the lower row. the same age. Additionally, the differential expression of Apof was gender-related: the difference between the males was much bigger than that between the females of the two strains. The fold increase was 53.75 in 12-week-old males and 51.46 in 4-week-old males versus 5.24 in 12-week-old females and 4.56 in 4 -week-old females. The fold decrease in expression of Mgll was also strainspecific: a lower expression was detected in all NOD groups in contrast to BALB/c controls at the same age. Differential expressions of Apof, Lipc, Mgll and Pmvk were also observed in 12-week-old male NOD SCID mouse LG versus the BALB/c control. The fold changes were $20.33,4.84,0.35$ and 10.37 respectively (Table 3 ).

In contrast to the genes described above, Apoe, Abcd 1 and Abcg1 were upregulated (2.11-, 2.18- and 5.20-fold respectively) more than 2 folds only in 12-week-old male NOD mouse LG (Table 2) but not in matched NOD SCID mouse LG (Table 3) when compared to the BALB/ c controls. There was no change in the mRNA abundance in female NOD mouse LG of both age groups versus the controls. (Table 2)

Comparison of gene expressions in LG between different genders in age-matched mice within the same strain: The results of these comparisons are summarized in Table 4. The increased expression of Apof and Lipc genes was entirely gender-specific: the mRNA levels of Apof and Lipc were higher in NOD male mouse LG relative to NOD female LG and higher in BALB/C males than in BALB/ c females at 12-week and 4-week age respectively. The fold changes in NOD mouse LG were 57.98 and 132.83 , and in BALB/c mice 5.88 and 11.11. The differential expression of Apoe and Abcg1 was observed only in the LG of NOD mice at 12 weeks of age: the mRNA levels of Apoe and Abcg1 were 2.26- and 6.04-fold in NOD males relative to females. mRNA levels of these two genes were not distinguishable between 4-week-old NOD males and females, or between BALB/c males and females at the both ages. The differential expression of Pmvk mRNA between males and females was only observed in 12-week groups in both NOD and BALB/c mice apparently due to decreased mRNA levels by age in the females.

\subsubsection{Comparison of gene expression between gender-matched}

\section{2- and 4-week old mice within the same strain}

The results of these comparisons are summarized in Table 5. The expression of the Apof gene was moderately decreased in both male NOD and BALB/c mice, but moderately increased in female NOD and BALB/C mice by age. The expression of Lipc was moderately decreased in 12-week-old NOD females and BALB/c males but remained unchanged by age in NOD males and BALB/c females. The expression of Mgll was decreased by age in both strains and both genders. The expression of Pmvk decreased in both 12-week-old NOD females and possibly in 12-week-old BALB/c females but not in either group of males.

Table 3

Comparisons of gene expressions in LG and liver from NOD, NOD SCID and BALB/c mice by real-time RT-PCR.

\begin{tabular}{|c|c|c|c|c|}
\hline Gene & $\begin{array}{l}\text { FC NOD(M)/ } \\
\text { BALB(M) } \\
\text { (LG/LG, } 12 \text { wks) }\end{array}$ & $\begin{array}{l}\text { FC NOD S(M)/ } \\
\text { BALB(M) } \\
\text { (LG/LG, } 12 \text { wks) }\end{array}$ & $\begin{array}{l}\text { FC NOD(M)/ } \\
\text { BALB(M) } \\
(\mathrm{LV} / \mathrm{LV}, 12 \mathrm{wks})\end{array}$ & $\begin{array}{l}\text { FC NOD S(M)/ } \\
\text { BALB(M) } \\
(\mathrm{LV} / \mathrm{LV}, 12 \mathrm{wks})\end{array}$ \\
\hline Abcd1 & 2.18 & 0.98 & 1.20 & 0.81 \\
\hline Abcg1 & 5.20 & 1.22 & 1.39 & 0.65 \\
\hline Apoe & 2.11 & 1.35 & 0.87 & 1.08 \\
\hline Apof & 53.75 & 20.33 & 1.01 & 1.03 \\
\hline Lipc & 4.00 & 4.84 & 0.68 & 0.57 \\
\hline Mgll & 0.33 & 0.35 & 1.06 & 1.18 \\
\hline Pmvk & 6.14 & 10.37 & 1.53 & 1.58 \\
\hline
\end{tabular}

FC: fold change, obtained by calculation as described in Materials and methods. BALB: BALB/c. NOD S: NOD SCID. M: male. F: female. LV: liver. All fold changes equal to or greater than 2.00 are in bold. All fold changes equal to or smaller than 0.5 are in italics. The genes reportedly involved in lipid transport are listed in the top row and genes involved in lipid metabolism in the lower row. 
Table 4

Comparison of gene expressions in LG between different genders in age-matched mice within the same strain and at the same age by real-time RT-PCR.

\begin{tabular}{lllll}
\hline Gene & FC NOD(M)/ & FC BALB(M)/ & FC NOD(M)/ & FC BALB(M)/ \\
& NOD(F) (12 wks) & BALB(F) (12 wks) & NOD(F) (4 wks) & BALB(F) (4 wks) \\
\hline Abcd1 & 1.38 & 0.78 & 0.83 & 1.14 \\
Abcg1 & $\mathbf{6 . 0 4}$ & 1.56 & 1.35 & 1.27 \\
Apoe & $\mathbf{2 . 2 6}$ & 1.07 & 1.22 & 1.12 \\
Apof & $\mathbf{5 7 . 9 8}$ & $\mathbf{5 . 8 8}$ & $\mathbf{1 3 2 . 8 3}$ & $\mathbf{1 1 . 1 1}$ \\
& & & & \\
Lipc & $\mathbf{1 5 . 0 3}$ & $\mathbf{1 1 . 1 1}$ & $\mathbf{1 1 . 3 6}$ & $\mathbf{2 2 . 5 0}$ \\
Mgll & 0.91 & 0.57 & 1.67 & 1.61 \\
Pmvk & $\mathbf{2 . 8 8}$ & $\mathbf{3 . 3 3}$ & 0.39 & 1.30 \\
\hline
\end{tabular}

FC: fold change, obtained by calculation as described in Materials and Methods BALB: BALB/c. M: male. F: female. All fold changes equal to or greater than 2.00 are in bold. All fold changes equal to or smaller than 0.5 are in italics. The genes reportedly involved in lipid transport are listed in the top row and genes involved in lipid metabolism in the lower row.

\subsubsection{Comparison of gene expression between LG and liver}

The tissue specificity of the differential expressions of the genes described above was determined by real-time RT-PCR. The total RNAs from LGs of NOD, NOD SCID and BALB/c male mice were compared to that from the matched livers. All the genes tested showed an LG-specific alteration in their expressions (Table 3).

\subsection{Altered distribution of Apo-F protein in lacrimal acinar} cells of male NOD mice

Because of the striking upregulation of Apof as early as 4 weeks of age, in concert with its possible function in cholesterol efflux, its cellular distribution was examined. Immunofluorescence staining was used to localize the Apo-F protein and to investigate if the protein abundance was correlated with the increased mRNA levels in acinar cells of NOD mice as shown in Fig. 2. Apo-F immunofluorescence in LG from 12-week-old male BALB/c mice was localized to distinctive dotshaped structures at or adjacent to the basolateral plasma membranes in the acinar cells. When observed above and below the plane of focus, these labeled areas appeared to form continuous linear structures, suggesting that they might be localized to a tubular structure moving through the focal plane (data not shown). The Apo-F positive areas appeared close to or at the plasma membrane as they physically colocalized with actin filaments as shown in the section of 12-weekold BALb/c mouse. The extent of colocalization of Apo-F with the lysosomal and late endosomal marker, Lamp2, in the same analysis showed that the Apo-F-enriched structures were not commonly colocalized with lysosomes/late endosomes, although traces of Apo-F protein were detected in some lysosomes/late endosomes when using

\section{Table 5}

Comparison of gene expressions in LG between different ages in gender-matched mice within the same strain and the same gender by real-time RT-PCR.

\begin{tabular}{|c|c|c|c|c|}
\hline Gene & $\begin{array}{l}\text { FC NOD (M)/ } \\
\text { NOD (M) } \\
(12 \text { wks/4 wks) }\end{array}$ & $\begin{array}{l}\text { FC NOD }(F) / \\
\text { NOD (F) } \\
(12 \text { wks/4 wks) }\end{array}$ & $\begin{array}{l}\text { FC BALB }(\mathrm{M}) / \\
\text { BALB }(\mathrm{M}) \\
(12 \text { wks/4 wks) }\end{array}$ & $\begin{array}{l}\text { FC BALB }(F) / \\
\text { BALB (F) } \\
(12 \text { wks/4 wks) }\end{array}$ \\
\hline Abcg1 & 2.13 & 1.02 & 0.51 & 0.95 \\
\hline Apoe & 3.31 & 1.22 & 1.42 & 1.70 \\
\hline Apof & 0.61 & 1.61 & 0.53 & 2.00 \\
\hline Lipc & 0.91 & 0.62 & 0.53 & 1.12 \\
\hline Mgll & 0.21 & 0.33 & 0.18 & 0.49 \\
\hline Pmvk & 0.81 & 0.12 & 1.54 & 0.59 \\
\hline
\end{tabular}

FC: fold change, obtained by calculation as described in Materials and Methods BALB: BALB/c. M: male. F: female. All fold changes equal to or greater than 2.00 are in bold. All fold changes equal to or smaller than 0.5 are in italics. The genes reportedly involved in lipid transport are listed in the top row and genes involved in lipid metabolism in the lower row. much milder permeabilization methods (data not shown). Surprisingly, when Apo-F immunofluorescence was evaluated in LG from 12-week-old male NOD mice, the characteristic dot-shaped basolateral labeling pattern in the LG of matched BALB/c mice was rarely detected; instead most of the label was located away from the basolateral membrane and detected adjacent to the actin-enriched apical plasma membrane region, in a location consistent with enrichment in acinar secretory vesicles. The altered protein abundance within the acinar cells between the two strains could not be accurately estimated since the areas occupied by Apo-F were significantly different, representing bright small puncta in BALB/c mouse LG and intense whereas more diffuse subapical vesicular labeling in NOD mouse LG.

As shown in Table 4, Apo-F was significantly upregulated as early as 4 weeks of age in male NOD mouse LG. The change in Apo-F protein distribution seen at 12 weeks of age was also detected in younger mice. The same enrichment of Apo-F in secretory vesicle like-structures was observed in 4-week-old male NOD mice (Fig. 2). However, the staining analysis did not clearly localize the Apo-F protein in the acinar cells from LG of 4 -week-old male BALB/c mice. It was possible due to the scattering of the protein in endoplasmic reticulum and Golgi apparatus in younger mouse as evidenced by the dim cytoplasmic staining in the acinar cells, other than gathering near or at the basolateral membrane as in older mouse. This speculation was supported by the observation that the positive staining of Apo-F at the basal lateral region of acinar cells from 18-week-old BALB/c mice was generally more intensive than from 12-week-old BALB/c mice (data not shown).

\subsection{Colocalization of Apo-E with Apo-F in healthy lacrimal acinar cells}

The results from histochemistry, lipid characterization and gene expression profiling suggested a defect in metabolism or transport of cholesterol in the acinar cells from the male NOD mouse. Apo-E was logically considered as a potentially important player in response to the lipid accumulation according to its previously proven functions in lipid homeostasis in both human and animals (Ghiselli et al., 1981; Mabuchi et al., 1989; Kurosaka et al., 1991; Plump et al., 1992; Zhang et al., 1992; Linton et al., 1995). Its mRNA level was also modestly increased (2.11-fold) in the LG of male NOD mice. Immunofluorescence staining was also conducted to localize the Apo-E protein in LG samples as shown in Fig. 3. Apo-E was detected in a bead-like pattern associated with or near the basolateral domains of the acinar cells in BALB/c (panel B), NOD (panel F) and NOD SCID mice (panel J) in a pattern similar to that seen for Apo-F in BALB/c mice (panel C), but was distinct from the pattern seen for Apo-F in NOD (panel G) and NOD SCID mice (panel K). Apo-F was thus highly colocalized with Apo-E in the LG of BALB/C mice (panel D) but found in distinct locations relative to Apo-E in the LG of NOD (panel H) and NOD SCID mice (panel L).

\subsection{Apo-F is detected in LG tissues of both NOD and $B A L B / c$ mice but only in tears of NOD mice}

The result of immunofluorescence staining suggested secretory vesicles were a likely location where Apo-F protein was missorted to in the acinar cells of NOD mouse LG. To further verify this possibility, LG lysates and tear fluid were prepared from male NOD and BALB/C mice and analyzed for Apo-F by Western blotting. Analysis of LG lysates (Fig. 4A), revealed a signal at $\sim 37 \mathrm{kD}$ corresponding to the unmodified form of the pre-processed protein. No signal was recognized by the pre-immune serum in any samples (lanes 1-3). The $37 \mathrm{kD}$ signal (lanes 5-8) co-migrated with that for purified recombinant Apo-F (lane 4). No clear signal at the position of $\sim 30 \mathrm{kD}$ corresponding to the reported mature form of human Apo-F (Day 

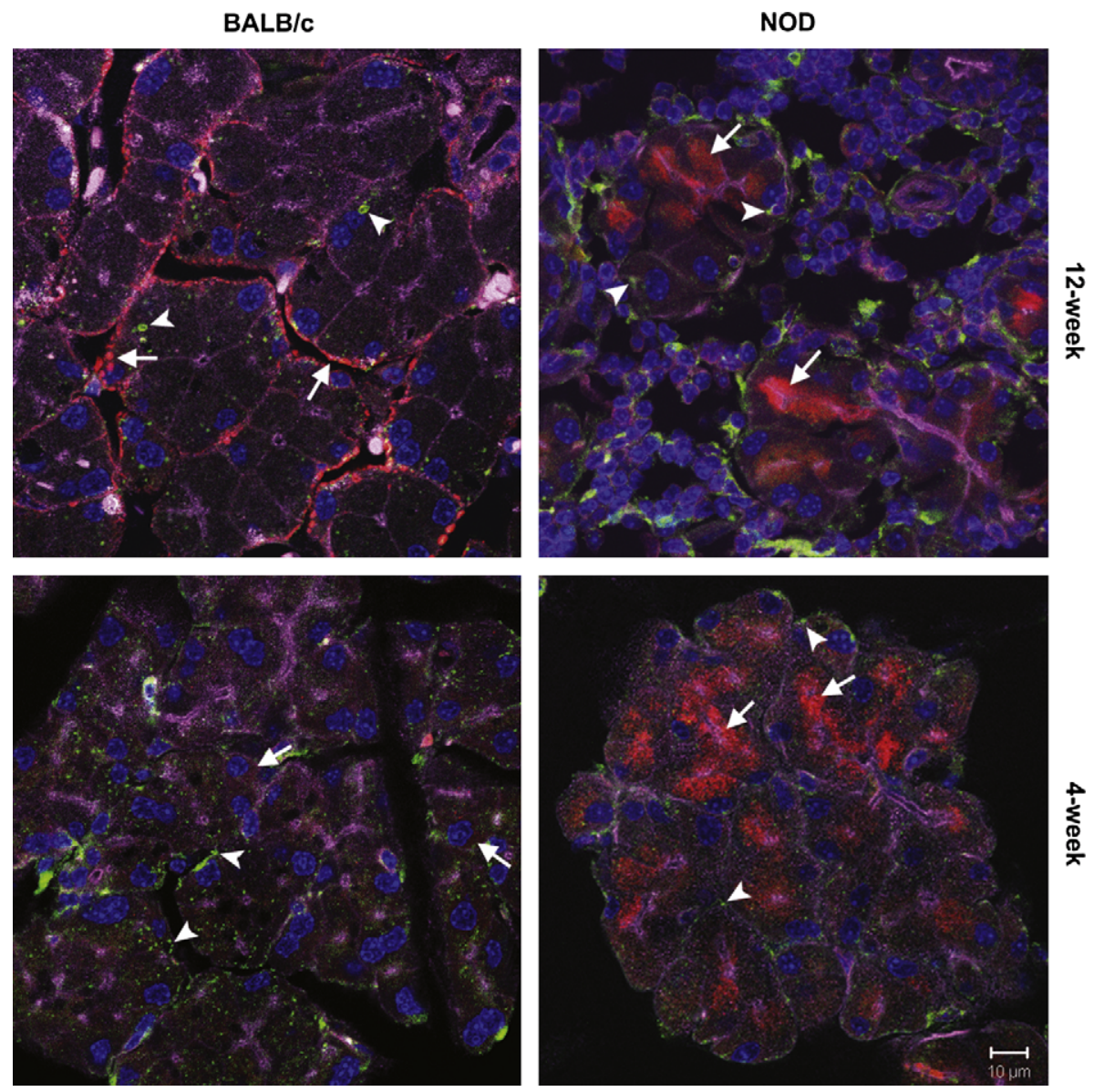

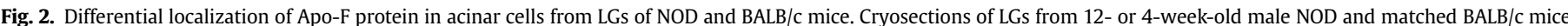

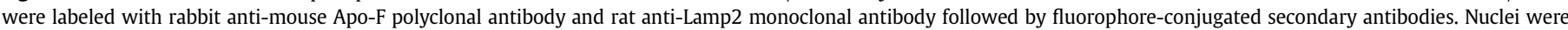

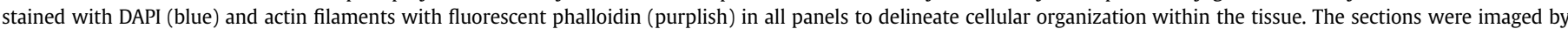

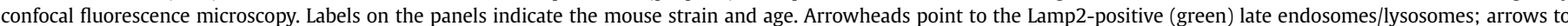

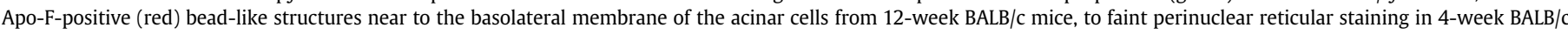

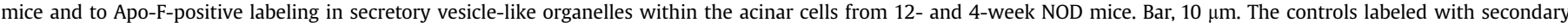
antibodies showed no fluorescence for Apo-F (data not shown).

et al., 1994; Wang et al., 1999; Morton et al., 2008) was detected, although there were some weak signals in this region for both NOD and BALB/mice in LG lysates (data not shown). Western blotting analysis of tear fluid from the mice is shown in Fig. 4B. A band of 28-30 kD corresponding to the mature form of human Apo-F, was detected in pooled tears from 12 week male NOD mice (lane 3 ), while no band with same molecular weight was detected in pooled tears from matched BALB/c mice (lane 2), nor was any signal detected with pre-immune serum (lanes 4 and 5). Surprisingly, the 28-30 kD band was also detected in the tears of 4 week male NOD mice (lane 7) at an even higher intensity, but not in the tears of the matched BALB/c control (lane 6), suggesting that Apo-F upregulation and functional missorting are early events that precede the development of detectable inflammatory disease in the NOD mouse LG. Addition of excess recombinant Apo-F diminished the detection signal of the putative Apo-F protein in lysates (Fig. 4C, lanes 3 and 4) and in tears (lane 6), proving the specificity of the interactions between the antibody and the targets in the Western blotting analysis.

To confirm that the putative Apo-F present in NOD mouse tear was in fact glycosylated, we treated the collected tears from male NOD mice with Glyco ${ }^{\circledR}$-Sialidase $\mathrm{A}^{\mathrm{TM}} / \mathrm{NANase}$ III (N-acetylneuraminate glycohydrolase) and Glyko ${ }^{\circledR}$-O-Glycanase ${ }^{\circledR}$ (endo- $\alpha-\mathrm{N}$-acetylgalactosaminidase). Migration of a portion of the $28-30 \mathrm{kD}$ band became faster when treated with combined Sialidase A and O-
Glycanase as shown in Fig. 4D, lane 4 compared to the untreated (lanes 1 and 2). However, unlike the result reported from the study on human lipoprotein-bound Apo-F by Morton et al (Morton et al., 2008), treatment with Sialidase A alone did not change the migration of the putative Apo-F (lane 3) compared to the untreated. This result indicates that the Apo-F in the tear fluid is not modified by sialic acid. Additionally, the apparent molecular weight of the deglycosylated protein band was still bigger than the non-modified mature Apo-F (17-18 kD) as predicted by UniProtKB database after deglycosylation.

\subsection{Lipid efflux in lacrimal acini is primarily through basolateral routes}

The colocalization of the known lipid efflux factor, Apo-E, with the putative efflux factor, Apo-F, at the basolateral membrane in healthy mouse LG suggests that acini normally efflux lipids at the basolateral rather than apical route. To confirm this we measured CE values in pure lacrimal fluid, which would include materials secreted apically from acinar and ductal cells. Since the size of the mouse tear duct and difficulty of cannulation limits the isolation of sufficient lacrimal fluid for this analysis, we used rabbit lacrimal fluid. In rabbit tears the $\mathrm{CE}$ values averaged $32 \pm 19 \mu \mathrm{g} / \mathrm{dL}$ (Mean $\pm \mathrm{SD})(n=4)$. We have also conducted a detailed analysis of lipid profiles of plasma from male NOD and BALB/c mice to inspect if the cholesterol values exhibited 
$2^{\circ} \mathbf{A b}$
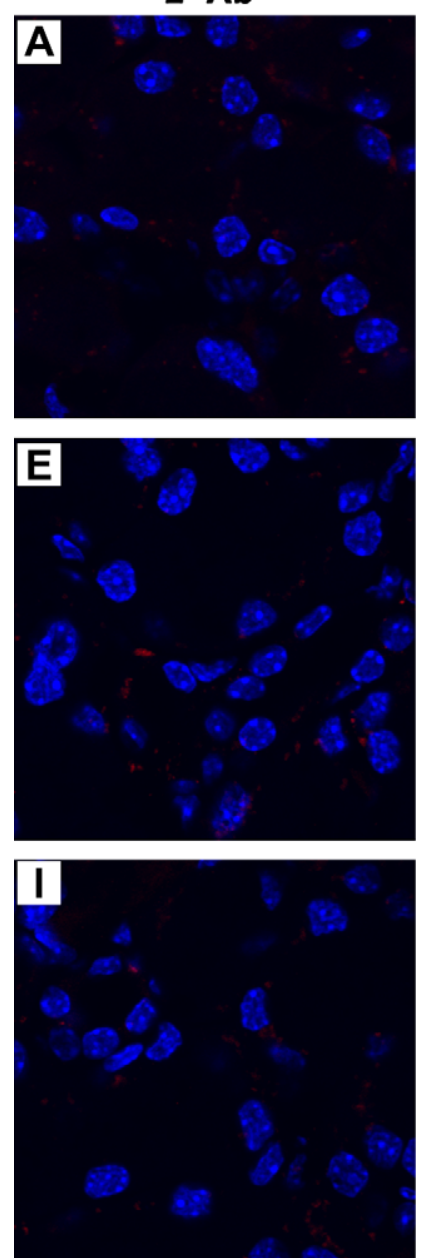

Apo-E
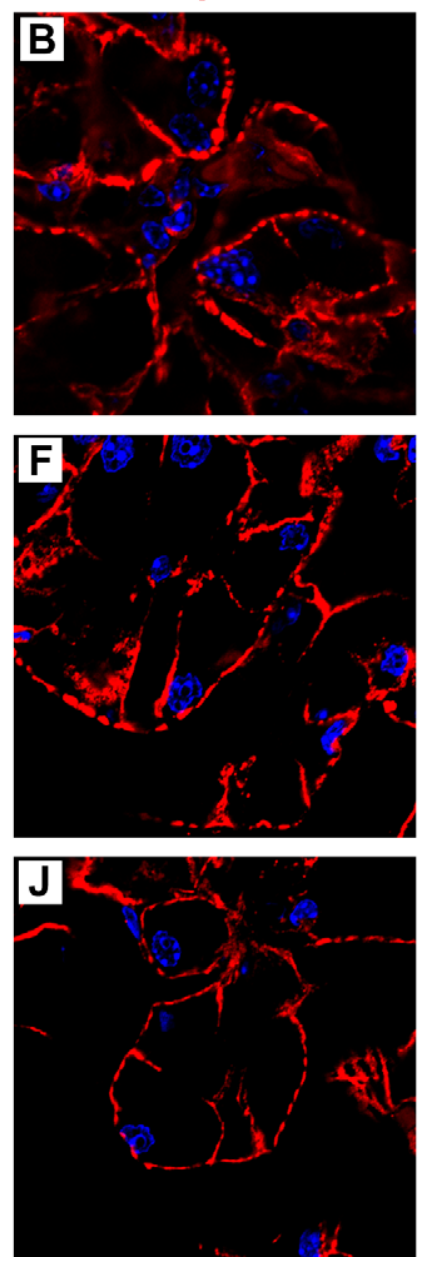

Apo-F
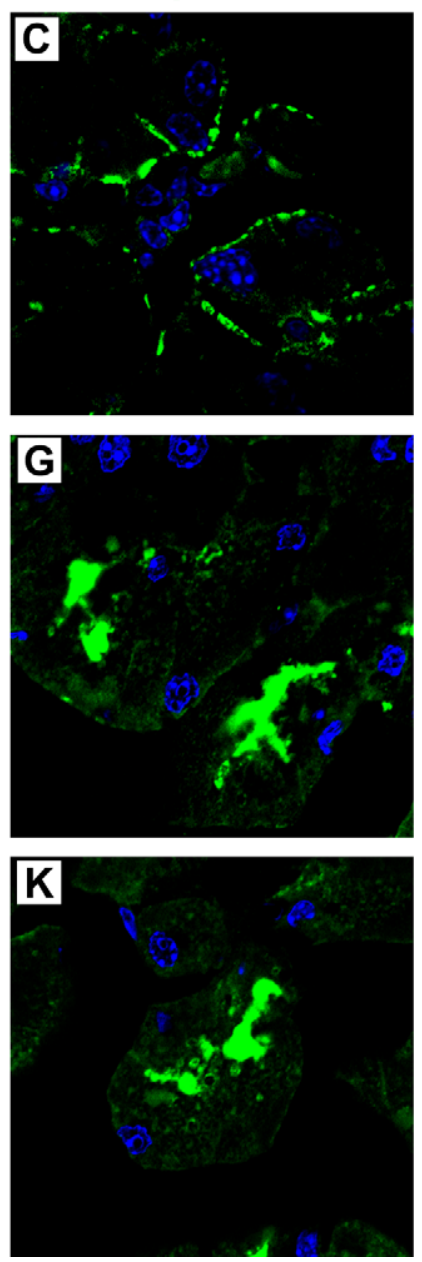

Apo-EIApo-F
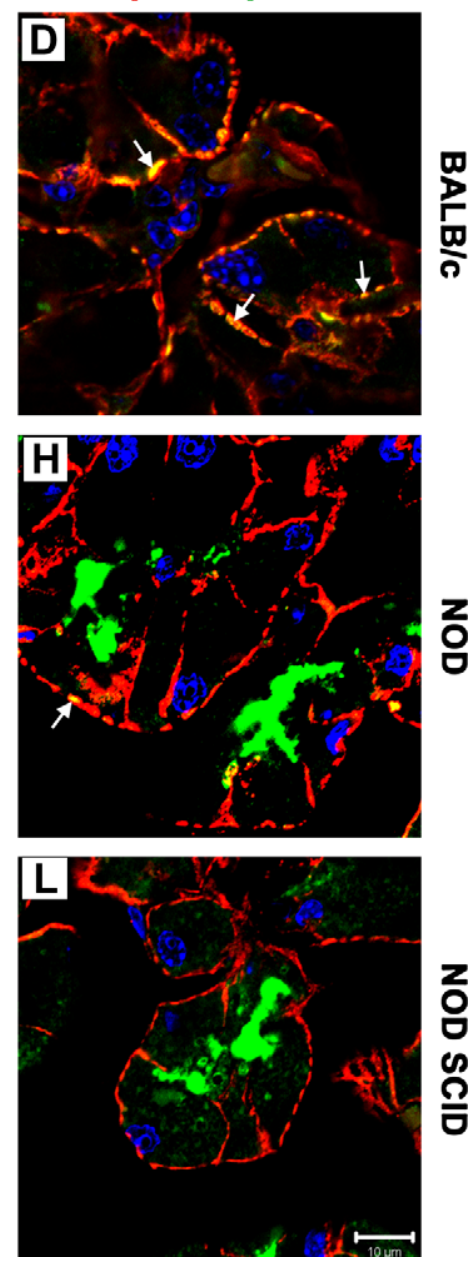

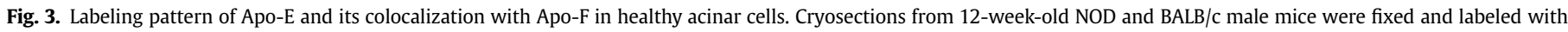

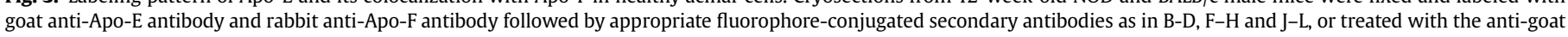

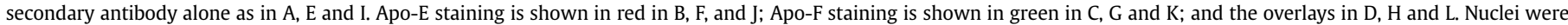

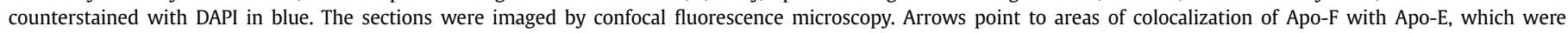
frequently observed in BALB/c mouse LG (D) but much less frequently detected in NOD (H) and NOD SCID (L) mouse LG. Bar, $10 \mu \mathrm{m}$.

major changes. The total cholesterol in the plasma of male BALB/C and NOD mice were $132 \pm 9 \mathrm{mg} / \mathrm{dL}$ and $105 \pm 5 \mathrm{mg} / \mathrm{dL}$ respectively. Clearly, the plasma level of cholesterol exceeds the lacrimal fluid level in excess of $3000 \times$, suggesting that the apical secretory pathway is not a major efflux route for cholesterol in the LG. The cholesterol in association with HDL, LDL and VLDL was $85 \pm 8 \mathrm{mg} / \mathrm{dL}, 16 \pm 3 \mathrm{mg} / \mathrm{dL}$ and $15 \pm 3 \mathrm{mg} / \mathrm{dL}$ respectively in plasma of 13-week-old male BALB/c mice $(n=10)$, and $66 \pm 4 \mathrm{mg} / \mathrm{dL}, 14 \pm 3 \mathrm{mg} / \mathrm{dL}$ and $14 \pm 3 \mathrm{mg} / \mathrm{dL}$ respectively in plasma of age- and gender-matched NOD mice $(n=15)$. Similar to patients with SjS (Lodde et al., 2006), both total cholesterol and HDL-cholesterol in the male NOD mice were significantly lower relative to the BALB/c control $(P<0.001)$. The lower HDL-cholesterol in the circulation of NOD mouse than in BALB/c mouse indicates a lower capacity of cholesterol efflux from peripheral tissues of NOD mouse.

\subsection{Lipid deposition and immune cell infiltration are coincident in LG of male NOD mouse}

To determine if the homeostatic imbalance of lipids might be a causal factor for the autoimmune disorder, the temporal relation between the onset of lipid accumulation and immune cell infiltration in LG was defined more precisely by ORO staining. LG sections from 5 age groups (4-6, 8, and 12 weeks) from NOD and age-matched BALB/c mice of both genders were examined under the light microscope and photographed as shown in Fig. 5. Quantitative results of lipid accumulation are summarized in Fig. 6. In some samples, lipid droplets began to accumulate in acinar cells in an apparently random distribution in the LG of NOD males at 5 weeks of age. Noticeable lipid deposition was consistently identified in the LG of NOD male mice starting from 6 weeks of age as shown in Fig. 5, panels C-E. The severity increased with increased age. $100 \%$ of the LGs of male NOD mice at aged 6 weeks or older was lipid depositionpositive and the lipids were detected homogeneously across the acini by 8 weeks of age. All age groups of NOD females, BALB/c males and BALB/C females failed to exhibit noticeable lipids and the staining results from the 12-week-old groups are presented as examples in panels I, G and $\mathrm{K}$.

In the LG of male NOD mice, lymphocytes originated in the ductal regions at 6 weeks of age, marked in Fig. 5, panel C, migrating and propagating radially into extracellular space of acini 

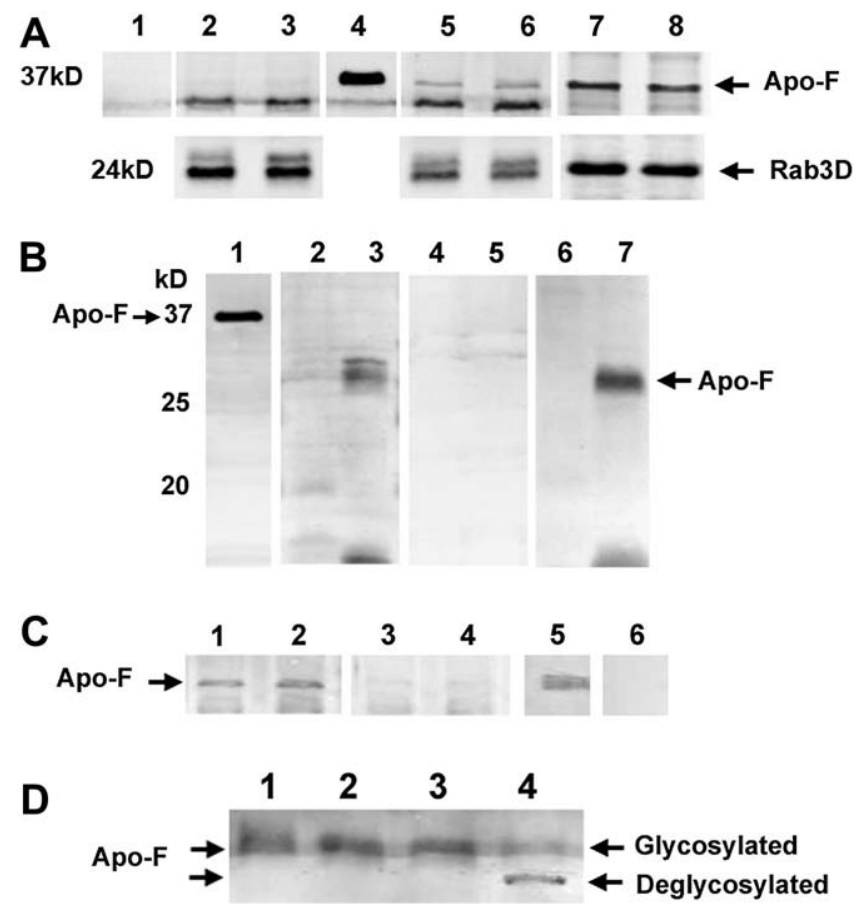

Fig. 4. Detection of Apo-F protein in both LG and tear from male NOD mice. Pretreated or untreated equal amount of clarified pooled LG lysates $(100 \mu \mathrm{g})$ and equal volume of pooled tears $(2 \mu \mathrm{L})$ from male NOD and BALB/c mice, as indicated below, were resolved by SDS-PAGE gels, followed by Western blotting analysis. A: Detection of Apo-F in LG lysates. 20 ng of purified recombinant His-tagged mouse full length Apo-F protein without signal peptide (lanes 1 and 4) were run in parallel with lysates from LGs of BALB/c mice at 12 weeks (lanes 2 and 5) and 4 weeks (lane 7), or of NOD mice at 12 weeks (lanes 3 and 6 ) and 4 weeks (lane 8). Lanes 1-3 were blotted with preimmune serum; lanes $4-8$ with anti-Apo-F antibody. A $\sim 37 \mathrm{kD}$ band corresponding to the position of the recombinant protein (lane 4) was detected by the antibody in lysates (lanes 5-8) but not by the pre-immune serum (lanes 1-3). Rab3D, a stably expressed protein in acinar cells, was blotted in parallel with rabbit anti- Rab3D antiserum to confirm equal protein loading. B: Detection of Apo-F in tears. Recombinant Apo-F protein (lane 1) as in A was loaded as a positive control in parallel with the tear samples from 12-week-old BALB/c (lanes 2 and 4) and NOD (lanes 3 and 5) mice and 4-week-old BALB/c (lane 6) and NOD (lane 7) mice. Lanes 1-3, 6 and 7 were blotted with anti-Apo-F antibody; lanes 4 and 5 with pre-immune serum. A 28-30 kD band migrating faster than the recombinant protein was detected by the antibody in samples from both 12-week and 4-week NOD mice (lanes 3 and 7, respectively) but not in that from BALB/c mice (lanes 2 and 6), C: Blockage of the antibody interaction with endogenous Apo-F in LG lysates or tears by recombinant Apo-F protein. The gland lysates from 4-week-old BALB/c (lanes 1 and 3) and NOD (lanes 2 and 4) mice or pooled tears from 4-week-old NOD mice (lanes 5 and 6 ) were blotted with anti-Apo-F antibody pre-incubated without (lanes 1,2 and 5) or with (lanes 3, 4 and 6) $1.5 \mu \mathrm{g}$ of recombinant Apo-F protein. D: Deglycosylation of tear proteins with Glyco ${ }^{\circledR}$-Sialidase $\mathrm{A}^{\mathrm{TM}}$ and Glyko ${ }^{\circledR}$-O-Glycanase ${ }^{\circledR}$. Pooled tears from 12 -week-old NOD mice were treated with the two enzymes: lane 1, control with neither buffer nor enzyme; lane 2, control with buffer only; lane 3, with buffer and Sialidase A; and lane 4, with buffer and both enzymes.

to form infiltrating foci in large size by 8-12 weeks (panels D and E). $100 \%$ of the LGs were positive for both lipid deposition and lymphocytic infiltration by 8 weeks. Heavily loaded lipids and extensively infiltrating lymphocytes concomitantly occurred in the gland of 12-week-old male NOD mice (panels $\mathrm{H}$ and L). Lipid deposition in the LG of male NOD SCID mice at 12 weeks of age was comparable to that of the matched NOD mice except for a lack of detectable lymphocytic foci (panel F). These LGs appeared otherwise healthy and no noticeable tissue necrosis, suggesting that lipid deposition alone is tolerated by the acinar cells. The LGs of female NOD SCID mice appeared similar to that of female NOD mice, with little lipid deposition and without detectable infiltrating immune cells (panel J).

\section{Discussion}

In this study we demonstrate that the $\mathrm{CE}$ content within the acinar cells of the male NOD mouse LG is significantly increased, with detectable lipid droplet deposition occurring as early as 5-6 weeks of age. To understand the origin of the lipid deposition, a closer look at the expression profiles was undertaken for the genes involved in lipid metabolism and transport, which were altered in the LG of NOD mouse. The genes differentially expressed can be divided into four categories: 1) genes for which expression is profoundly higher in both 12- and 4-week-old male NOD mice (Apof); 2) genes for which expression is higher in both male and female and 12-and 4-week-old NOD mice (Lipc and Pmyk); 3) genes for which expression is higher only in 12-week-old NOD mice (Apoe, Abcd1 and Abcg1); and 4) genes for which expression is lower in both male and female and 12and 4-week-old NOD mice (Mgll). We suggest that the genes in the first category most likely play a causal role in the lipid deposition. Genes in the second and fourth category may contribute to background susceptibility or progression of lipid deposition in the NOD mouse background but are not completely correlated with the onset and gender bias associated with lipid deposits. Genes in the third category are upregulated after lipid deposition is initiated, so they may contribute to modulate lipid transport or efflux. Since the LG of male NOD mice used for microarray and real-time RT-PCR were infiltrated with inflammatory cells, these mRNAs may be produced by either acinar cells or infiltrating cells.

One of our most striking observations was the significant upregulation of the Apof gene. Among all the apolipoproteins, Apof was the only gene which displayed a markedly increased expression in male NOD mouse LG compared to the BALB/c control. The Apof mRNA level in LG of male NOD mouse was much higher ( $>50$-fold) than the matched BALB/c control at both 4 weeks and 12 weeks of age, whereas there was a much smaller difference (4-5-fold) between the female LG of the two strains. The upregulation therefore correlates with the predisposition to lipid deposition. Additionally, the Apof mRNA level was increased by 20-fold in the LG of male NOD SCID male mice compared to the BALB/c control, but to a lesser extent than the matched NOD mice (Table 3). The higher upregulation in NOD than in NOD SCID mice thus is apparently influenced by the disease process. Interestingly, the livers of NOD male mice expressed a similar level of Apof mRNA relative to the BALB/c controls (Table 3 ), indicating that the differential expression was highly LG-specific.

\subsection{Apo-F may be functionally involved in lipid efflux and disabled in NOD mouse $L G$}

Previous studies have demonstrated Apo-F within HDL (Olofsson et al., 1978; Vaisar et al., 2007) and LDL (Wang et al., 1999; Morton et al., 2008), and showed its association with cholesterol and CE in lipoproteins (Koren et al., 1982). It functions in vitro as a lipid transfer inhibitor protein (LTIP) to inhibit lipid transfer protein (LTP-I)-mediated CE, triglyceride and phosphatidylcholine transfers and phospholipid transfer protein (LTP-II)-mediated phosphatidylcholine transfer (Nishide et al., 1989; Wang et al., 1999). Our study, together with previously published results, suggests at least two possibilities for the function of Apo-F in LG. First, it may play a role as a lipid transport inhibitor by negatively modulating the cholesterol influx from the interstitium into the cell at the basolateral membrane, consistent with its location in 12 week male BALB/c mouse LG. The incorrect sorting of Apo-F to secretory vesicles in male NOD mouse LG may disable this mechanism, resulting in increased intake of cholesterol and formation of excessive CE droplets. Alternatively, it may play a role in stimulating the cholesterol efflux at the basolateral membranes of the 

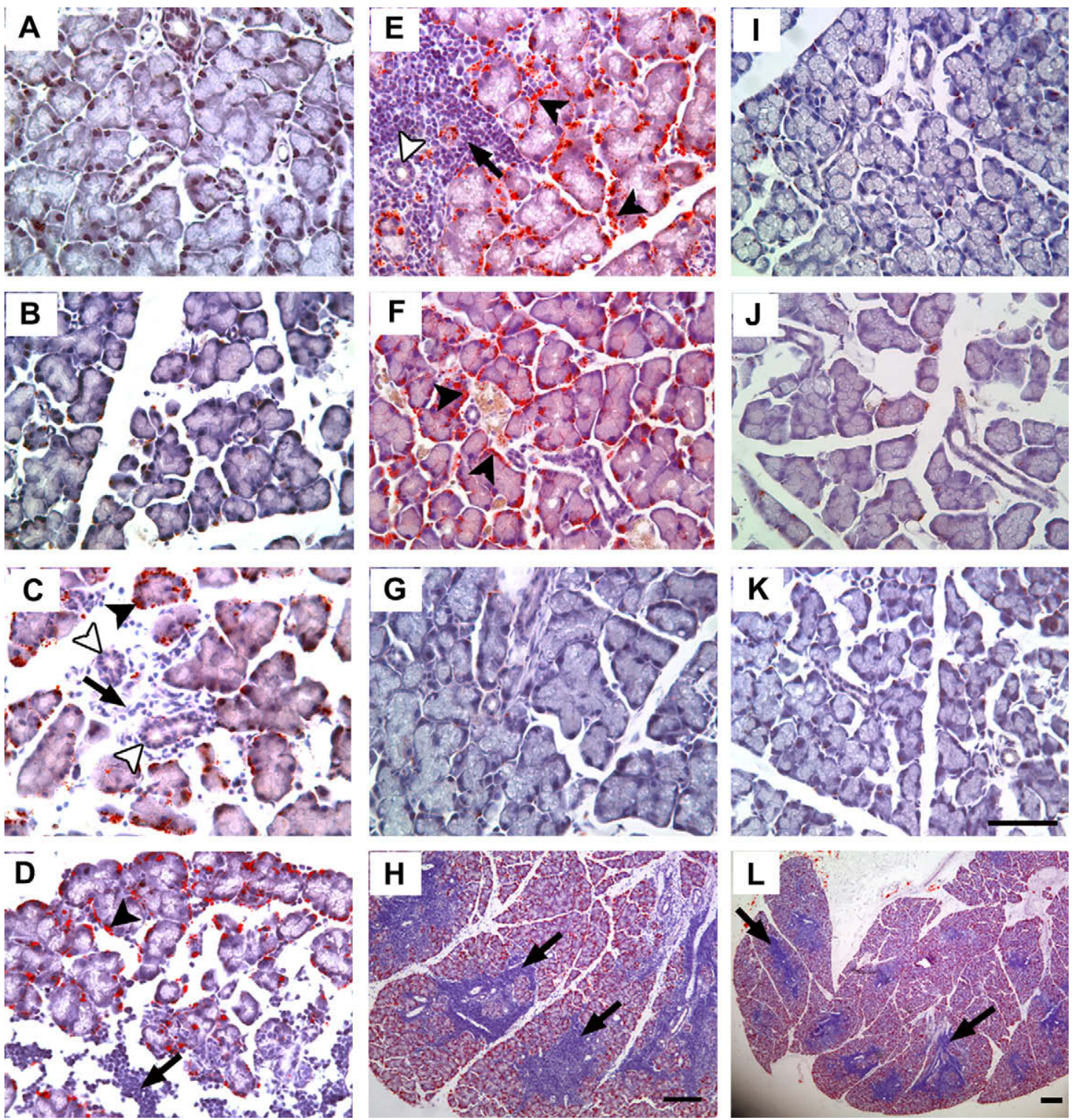

Fig. 5. Coincident lipid accumulation and lymphocytic infiltration by age in LGs of NOD and BALB/c mice. Cryosections of LGs from NOD and BALB/c mice of different genders and at different ages were stained with ORO and counterstained with hematoxylin prior to imaging by light microscopy. A-E, LGs from 4-, 5-, 6-, 8-, and 12-week-old male NOD mice respectively; F-L, LGs from 12-week-old mice: F, male NOD SCID; G, male BALB/c; I, female NOD; J, female NOD SCID; K, female BALB/c; H and L, male NOD. Arrowheads point to areas enriched in ORO-positive lipid droplets (in red); unfilled arrowheads to lacrimal duct regions; arrows to hematoxylin-stained nuclei of infiltrating lymphocytic foci (in blue). Bars in panels $\mathrm{H}, \mathrm{K}$ and $\mathrm{L}, 50 \mu \mathrm{m}$. All the sections were photographed at the same magnification except $\mathrm{H}$ and $\mathrm{L}$.

acinar cells. The incorrect sorting of Apo-F may again interrupt this function, resulting in accumulation of endogenous cholesterol and formation of CE droplets. It should be noted that the missorting of Apo-F protein to the apical membrane and consequent increase in this protein in tear fluid occurs as early as 4 weeks in the male NOD mouse LG, prior to any detectable lipid deposition.

\subsection{Lacrimal fluid may constitute the major excretion} path of excess Apo-F in $L G$

Although Western blotting analysis did not indicate a large increase in Apo-F protein abundance in the tissue lysates in contrast to the remarkable increase in Apof mRNA in the LG of NOD mice versus the BALB/c controls, the exclusive presence of Apo-F in tear fluid from male NOD mice may explain this finding. Apo-F protein in the NOD mouse LG appears to be secreted incorrectly at the apical plasma membrane, rather than being localized normally at the basolateral domain of the cell as seen in BALB/c mouse LG. The upregulation of Apof mRNA is thus a possible consequence of the shortage of functional Apo-F protein in the right compartment of the acinar cells. The redistribution of Apo-F to secretory vesicles as early as 4 weeks of age in the male NOD mouse suggests that the normal function of this protein is abolished, and this disruption may contribute to the deposition of CE within the acinar cells.

\subsection{Apo-E may functionally interact with Apo-F to modulate lipid efflux}

Apo-E is an apolipoprotein known to play critical and versatile roles in lipid homeostasis. One of the recognized functions of Apo-E is facilitating the lipid efflux process by escorting the cholesterol molecules to HDL (Basu et al., 1983; Dory, 1989). Additionally, Apo-E 


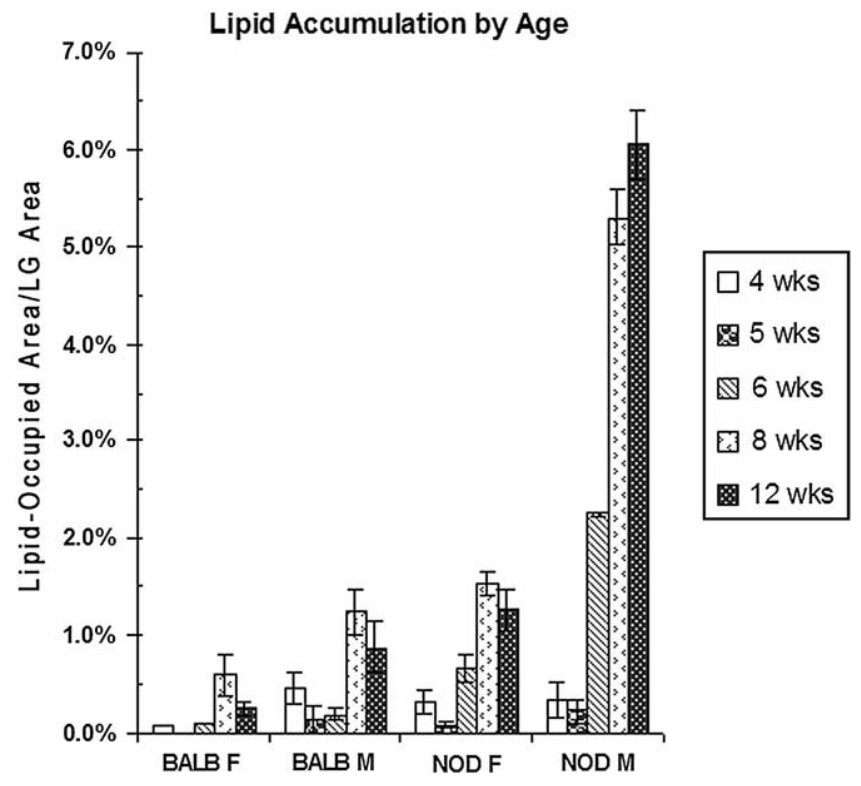

Fig. 6. Accelerated lipid accumulation by age in LG of male NOD mouse. The OROtreated tissue sections from different gender and age groups of mice were photographed under a light microscope. As described in Methods, multiple images covering the whole or majority of the LG were acquired and analyzed with image quantification software MetaMorph. Both ORO-positive area and total gland area were quantified in pixels. The extent of lipid deposition was expressed as the average percentage of ORO-positive area relative to the total LG area analyzed. Data are presented as Mean \pm SEM. $M=$ male; $F=$ female.

participates in the modulation of both innate and acquired immunity (Kelly et al., 1994; Mistry et al., 1995; Roselaar and Daugherty, 1998). The modestly elevated Apoe mRNA level in NOD mice verses in $\mathrm{BALB} / \mathrm{c}$ mice at 12 weeks suggests the upregulation of Apoe gene expression as a consequence of excessive cholesterol ester storage in the acinar cells. Since the upregulation of Apoe mRNA in NOD mice was more extensive than in NOD SCID mice, it may also reflect a response of the acinar cells to the ongoing inflammation. Previous studies have demonstrated Apo-E as an important regulator in cholesterol efflux from macrophages and other cell types (Mazzone and Reardon, 1994; Bellosta et al., 1995; Huang et al., 2006). The high abundance and the physical location at the basolateral domain of the acinar cells render Apo-E a likely player in cholesterol efflux from these cells. Thus, cholesterol efflux from acinar cells to HDL may be mediated by Apo-E localized to the basolateral domain of the acinar cells. Colocalization of Apo-E with Apo-F in healthy BALB/c mouse LG suggests a possible functional interaction between these two proteins in cholesterol efflux at the basolateral membrane.

Other proteins potentially involved in lipid-mediated processes are the lipocalins. Two lipocalins were identified as upregulated in the male NOD mouse LG by microarray analysis: lipocalin 2 (Lcn2) and lipocalin 11 (Lcn 11 ), by 2.42-fold and 1.94-fold respectively. Lcn 11 is not expressed in humans but the Lcn 2 protein is and has been implicated in diverse bioprocesses and reported to be an inflammatory marker closely related to obesity and insulin resistance (Wang et al., 2007).

\subsection{Lipid deposition is not a consequence of dacryoadenitis in NOD mouse}

Comparison of lipid accumulation and immune cell infiltration courses in the male NOD mouse LG, an experimental model of autoimmune exocrinopathy, revealed that both became readily detectable by 6 weeks of age, with the lipid accumulation occurring even earlier than lymphocytic infiltration in some mice. LGs of female NOD mice, which reportedly develop autoimmune exocrinopathy at a significantly delayed rate, were free of both lipid accumulation and immune cell infiltration until 22 weeks of age, the oldest age tested in our current study. This coincidence is applied to both male and female NOD mice, and has illustrated that the two pathogenic events are both gender-dependent. LGs of 12-week-old male NOD SCID mice, which are free of lymphocytic infiltration showed accumulation of lipid droplets similar to that of age- and gender-matched NOD mice, indicating that the lipid deposition is not a consequence of dacryoadenitis.

\subsection{Lipid deposition may contribute to development/progression of dacryoadenitis in NOD mouse}

Previous published studies have shown that knockout of the Abcg1 gene in C57BL/6 mouse caused lipid accumulation in type 2 pneumocytes, macrophages and in the extracellular space in lung, associated with simultaneous lymphocytic infiltration (Kennedy et al., 2005; Baldan et al., 2006). Accumulated lines of evidence have proved that Abcg1 functions as a lipid transporter on the pathway of lipid efflux. The interruption of lipid efflux by inactivation of the Abcg1 gene is therefore directly responsible for the lipid accumulation and possibly also responsible for the lymphocytic infiltration. As detected by gene expression profiling, Abcg1 mRNA was significantly increased in the LG of 12-week-old male NOD mouse corresponding to the massive lipid deposition, suggesting an attempt by the LG to remove the excess CE. However, there were few detectable lipid-laden foam cells in the LG until 24 weeks, although their percentage of the total infiltrating cells in NOD mice exceeded 25\% at age 12 weeks (unpublished data). These findings indicate either an impaired lipid efflux pathway in the NOD mouse acinar cells or a failure of uptake of cholesterol from the extracellular space by circulating HDL and/or macrophages. This deficiency and the coincident lymphocytic infiltration are reminiscent of the consequences of inactivation of the Abcg1 gene in mouse lung. Furthermore, as mentioned previously, MRI and CT scanning of LG and SG correlated premature lipid deposition with progression of sialoadenitis and dacryoadenitis in $\mathrm{SjS}$ patients (Izumi et al., 1997, 1998). The results of lipid classification and gene profiling, together with the published studies described above support the hypothesis that lipid deposition may contribute to development and/or progression of dacryoadenitis in this model system. However, we cannot rule out the possibility that the lipid deposition in NOD mouse only parallels the immune cell infiltration, without further proof.

Studies in recent years have linked aberrant lipid homeostasis to a variety of inflammatory and autoimmune diseases such as atherosclerosis, multiple sclerosis (MS) and systemic lupus erythematosus (SLE). The importance of immunological mechanisms in the progression of atherosclerotic lesions has been recognized (Hansson, 1999). Autoantibodies reacting with oxidized LDL have been cloned and characterized in human and animal models, and have been localized to the atherosclerotic plaques (Palinski et al., 1996; Shaw et al., 2001). In the LDL receptor-deficient mouse model, the titer of autoantibodies to oxidized LDL is correlated with the progression of atherosclerosis (Palinski et al., 1995). Women with SLE and cardiovascular disease also exhibit a significant expression of autoantibodies to oxidized LDL (Thiagarajan, 2001). In MS, the myelin sheath surrounding the neurons is damaged by autoimmune reactions (Genain et al., 1999). T-cells reactive to lipidbinding myelin basic protein (Mazzanti et al., 1998) or glycolipids (Shamshiev et al., 1999; Pender et al., 2003) and autoantibodies against GM3 ganglioside, phospholipids or sulfatide have been 
identified in MS patients (Uhlig and Dernick, 1989; Sadatipour et al., 1998; Ilyas et al., 2003). Lipid microarray analysis also demonstrated the presence of lipid-specific antibodies against sulfatide, sphingomyelin and oxidized lipids in cerebrospinal fluid from individuals with MS (Kanter et al., 2006). Finally, MRI and CT scanning of the SG and LG of SjS patients have suggested progressive lipid deposition is correlated with the development of inflammation and gland flow dysfunction (Izumi et al., 1997, 1998). These studies strongly suggest that imbalances in lipid homeostasis may trigger and/or contribute to the development and progression of autoimmune and other inflammatory diseases.

\subsection{Hypotheses of how lipid deposition might contribute to dacryoadenitis in NOD mouse}

There are several ways in which a homeostatic imbalance of lipids might contribute to the development and/or progression of lymphocytic infiltration in LG of male NOD mice. The normal structure and communication between cellular membrane compartments could be altered, thus affecting trafficking-dependent processes relevant to protein and lipid sorting, turnover, recycling and processing. It is established that immune signaling receptors utilize lipid rafts for their spatial organization, therefore changes in the organization of key signaling components in either immune cells or acinar cells might arise from direct changes in membrane composition (Dykstra et al., 2003). Changes in intracellular membrane trafficking could result in lack of fidelity of cellular protein sorting, leading to abnormal or accelerated trafficking to lysosomal or degradative pathways, and resulting in abnormal proteolytic processing. Such changes could eventually contribute to the release of potential autoantigens from the cell. Alternatively or in addition, the excess lipid deposition itself may alter signal transduction pathways within acinar cells and surrounding immune cells to produce proinflammatory cytokines, thereby contributing to dacryoadenitis. This possibility is reinforced by the findings that hyperlipidemic mice had increased expression of proinflammatory cytokines including IL-6, TNF- $\alpha$ and IL-1 $\beta$ compared to the controls (Kohn et al., 2005). These cytokines play pivotal roles in many different inflammatory diseases and they are indeed upregulated in LGs of both 12-week-old NOD and NOD SCID male mice versus the control group (unpublished data).

\subsection{Summary}

The lipid deposition in the LG of NOD mouse is gender- and agedependent, and correlated with but largely independent of immune cell infiltration. Several genes are implicated in the initial events involved in altered lipid metabolism in the LG of both pre-diseased and diseased NOD mice, and several other genes in lipid efflux or inflammation-induced events in immune or nonimmune cells once disease has been initiated in the NOD mouse LG. The results from the current study suggest altered intracellular lipid transport or lipid efflux or both as the underlying mechanisms of CE deposition. These changes may constitute a contributory factor to autoimmune dacryoadenitis in the LG of male NOD mouse. However the precise mechanism of the $\mathrm{CE}$ deposition and the direct roles of Apo-F, Apo-E and other proteins in this process as well as the direct linkage between the CE deposition and the autoimmunity remain to be elucidated.

\section{Acknowledgements}

This project was supported by NIH RO1 EY011386 to SHA. Additional support was provided by NIH EY017293 and EY016985. We acknowledge the contribution made by Vanderbilt Microarray
Shared Resource for their non-profit service for gene expression microarray. The Vanderbilt Microarray Shared Resource is supported by the Vanderbilt Ingram Cancer Center (P30 CA68485), the Vanderbilt Diabetes Research and Training Center (P60 DK20593), the Vanderbilt Digestive Disease Center (P30 DK58404), the Genomics of Inflammation Program Project Grant (1 P01 HL6744-01) and the Vanderbilt Vision Center (P30 EY08126). We acknowledge the instruments and services provided by the Analytical, Metabolic, and Instrumentation Cores and the Cell and Tissue Imaging Cores (NIH P30 DK048522) at the Research Center for Liver Diseases, University of Southern California. We thank Ben Huang for excellent technical assistance. We also greatly appreciate the critical comments of Dr. Austin Mircheff on the project and manuscript.

\section{References}

Ackman, R.G., 1981. Flame ionization detection applied to thin-layer chromatography on coated quartz rods. Methods Enzymol. 72, 205-252.

Baldan, A., Tarr, P., Vales, C.S., Frank, J., Shimotake, T.K., Hawgood, S., Edwards, P.A., 2006. Deletion of the transmembrane transporter ABCG1 results in progressive pulmonary lipidosis. J. Biol. Chem. 281, 29401-29410.

Basu, S.K., Goldstein, J.L., Brown, M.S., 1983. Independent pathways for secretion of cholesterol and apolipoprotein E by macrophages. Science 219, 871-873.

Bellosta, S., Mahley, R.W., Sanan, D.A., Murata, J., Newland, D.L., Taylor, J.M., Pitas, R.E., 1995. Macrophage-specific expression of human apolipoprotein E reduces atherosclerosis in hypercholesterolemic apolipoprotein E-null mice. J. Clin. Invest. 96, 2170-2179.

Brooks-Wilson, A., Marcil, M., Clee, S.M., Zhang, L.H., Roomp, K., Van Dam, M., Yu, L., Brewer, C., Collins, J.A., Molhuizen, H.O., Loubser, O., Ouelette, B.F., Fichter, K., Ashbourne-Excoffon, K.J., Sensen, C.W., Scherer, S., Mott, S., Denis, M., Martindale, D., Frohlich, J., Morgan, K., Koop, B., Pimstone, S., Kastelein, J.J., Genest Jr., J., Hayden, M.R., 1999. Mutations in ABC1 in Tangier disease and familial high-density lipoprotein deficiency. Nat. Genet. 22, 336-345.

Cartier, N., Sarde, C.O., Douar, A.M., Mosser, J., Mandel, J.L., Aubourg, P., 1993. Abnormal messenger RNA expression and a missense mutation in patients with X-linked adrenoleukodystrophy. Hum. Mol. Genet. 2, 1949-1951.

Cha, S., Nagashima, H., Brown, V.B., Peck, A.B., Humphreys-Beher, M.G., 2002. Two NOD Idd-associated intervals contribute synergistically to the development of autoimmune exocrinopathy (Sjogren's syndrome) on a healthy murine background. Arthritis Rheum. 46, 1390-1398.

Day, J.R., Albers, J.J., Gilbert, T.L., Whitmore, T.E., Mcconathy, W.J., Wolfbauer, G., 1994. Purification and molecular cloning of human apolipoprotein F. Biochem. Biophys. Res. Commun. 203, 1146-1151.

Ding, C., Macveigh, M., Pidgeon, M., Da Costa, S.R., Wu, K., Hamm-Alvarez, S.F., Schechter, J.E., 2006. Unique ultrastructure of exorbital lacrimal glands in male NOD and BALB/c mice. Curr. Eye Res. 31, 13-22.

Dory, L., 1989. Synthesis and secretion of apoE in thioglycolate-elicited mouse peritoneal macrophages: effect of cholesterol efflux. J. Lipid Res. 30, 809-816.

Dykstra, M., Cherukuri, A., Sohn, H.W., Tzeng, S.J., Pierce, S.K., 2003. Location is everything: lipid rafts and immune cell signaling. Annu. Rev. Immunol. 21, 457-481.

Folch, J., Lees, M., Sloane Stanley, G.H., 1957. A simple method for the isolation and purification of total lipides from animal tissues. J. Biol. Chem. 226, 497-509.

Fox, R.I., 2000. Sjogren's syndrome: current therapies remain inadequate for a common disease. Expert Opin. Investig. Drugs 9, 2007-2016.

Fox, P.C., 2007. Autoimmune diseases and Sjogren's syndrome: an autoimmune exocrinopathy. Ann. N Y Acad. Sci. 1098, 15-21.

Franklin, R.M., Kenyon, K.R., Tomasi, T.B.J., 1973. Immunohistologic studies of human lacrimal gland: localization of immunoglobulins, secretory component and Lactoferrin. J. Immunol. 110, 984-992.

Gasymov, O.K., Abduragimov, A.R., Prasher, P., Yusifov, T.N., Glasgow, B.J., 2005. Tear lipocalin: evidence for a scavenging function to remove lipids from the human corneal surface. Invest Ophthalmol. Vis. Sci. 46, 3589-3596.

Genain, C.P., Cannella, B., Hauser, S.L., Raine, C.S., 1999. Identification of autoantibodies associated with myelin damage in multiple sclerosis. Nat. Med. 5, 170-175.

Ghiselli, G., Schaefer, E.J., Gascon, P., Breser Jr., H.B., 1981. Type III hyperlipoproteinemia associated with apolipoprotein E deficiency. Science 214, 1239-1241.

Hansson, G.K., 1999. Inflammation and immune response in atherosclerosis. Curr. Atheroscler. Rep. 1, 150-155.

Huang, Z.H., Fitzgerald, M.L., Mazzone, T., 2006. Distinct cellular loci for the ABCA1dependent and ABCA1-independent lipid efflux mediated by endogenous apolipoprotein E expression. Arterioscler Thromb. Vasc. Biol. 26, 157-162.

Hunger, R.E., Carnaud, C., Vogt, I., Mueller, C., 1998. Male gonadal environment paradoxically promotes dacryoadenitis in nonobese diabetic mice. J. Clin. Invest. 101, 1300-1309.

Ilyas, A.A., Chen, Z.W., Cook, S.D., 2003. Antibodies to sulfatide in cerebrospinal fluid of patients with multiple sclerosis. J. Neuroimmunol 139, 76-80. 
Izumi, M., Eguchi, K., Nakamura, H., Nagataki, S., Nakamura, T., 1997. Premature fat deposition in the salivary glands associated with Sjogren syndrome: MR and CT evidence. AJNR Am. J. Neuroradiol 18, 951-958.

Izumi, M., Eguchi, K., Uetani, M., Nakamura, H., Takagi, Y., Hayashi, K., Nakamura, T., 1998. MR features of the lacrimal gland in Sjogren's syndrome. AJR Am. J. Roentgenol 170, 1661-1666.

Jonsson, R., Haga, H.J., Gordon, T.P., 2000. Current concepts on diagnosis, autoantibodies and therapy in Sjogren's syndrome. Scand. J. Rheumatol. 29, 341-348.

Kanter, J.L., Narayana, S., Ho, P.P., Catz, I., Warren, K.G., Sobel, R.A., Steinman, L., Robinson, W.H., 2006. Lipid microarrays identify key mediators of autoimmune brain inflammation. Nat. Med. 12, 138-143.

Kelly, M.E., Clay, M.A., Mistry, M.J., Hsieh-Li, H.M., Harmony, J.A., 1994. Apolipoprotein $\mathrm{E}$ inhibition of proliferation of mitogen-activated $\mathrm{T}$ lymphocytes: production of interleukin 2 with reduced biological activity. Cell Immunol. 159, 124-139.

Kennedy, M.A., Barrera, G.C., Nakamura, K., Baldan, A., Tarr, P., Fishbein, M.C., Frank, J., Francone, O.L., Edwards, P.A., 2005. ABCG1 has a critical role in mediating cholesterol efflux to HDL and preventing cellular lipid accumulation. Cell Metab. 1, 121-131.

Klenkler, B., Sheardown, H., Jones, L., 2007. Growth factors in the tear film: role in tissue maintenance, wound healing, and ocular pathology. Ocul. Surf 5, 228-239.

Kohn, L.D., Wallace, B., Schwartz, F., Mccall, K., 2005. Is type 2 diabetes an autoimmune-inflammatory disorder of the innate immune system? Endocrinology $146,4189-4191$.

Koren, E., Mcconathy, W.J., Alaupovic, P., 1982. Isolation and characterization of simple and complex lipoproteins containing apolipoprotein $\mathrm{F}$ from human plasma. Biochemistry 21, 5347-5351.

Kurosaka, D., Teramoto, T., Matsushima, T., Yokoyama, T., Yamada, A., Aikawa, T., Miyamoto, Y., Kurokawa, K., 1991. Apolipoprotein E deficiency with a depressed mRNA of normal size. Atherosclerosis 88, 15-20.

Linton, M.F., Atkinson, J.B., Fazio, S., 1995. Prevention of atherosclerosis in apolipoprotein E-deficient mice by bone marrow transplantation. Science 267, 1034-1037.

Lodde, B.M., Sankar, V., Kok, M.R., Leakan, R.A., Tak, P.P., Pillemer, S.R., 2006. Serum lipid levels in Sjogren's syndrome. Rheumatology (Oxford) 45, 481-484.

Mabuchi, H., Itoh, H., Takeda, M., Kajinami, K., Wakasugi, T., Koizumi, J., Takeda, R., Asagami, C., 1989. A young type III hyperlipoproteinemic patient associated with apolipoprotein E deficiency. Metabolism 38, 115-119.

Mazzanti, B., Vergelli, M., Riccio, P., Martin, R., Mcfarland, H.F., Liuzzi, G.M., Amaducci, L., Massacesi, L., 1998. T-cell response to myelin basic protein and lipid-bound myelin basic protein in patients with multiple sclerosis and healthy donors. J. Neuroimmunol 82, 96-100.

Mazzone, T., Reardon, C., 1994. Expression of heterologous human apolipoprotein E by J774 macrophages enhances cholesterol efflux to HDL3. J. Lipid Res. 35, 1345-1353.

Mistry, M.J., Clay, M.A., Kelly, M.E., Steiner, M.A., Harmony, J.A., 1995. Apolipoprotein E restricts interleukin-dependent T lymphocyte proliferation at the G1A/G1B boundary. Cell Immunol. 160, 14-23.

Morton, R.E., Gnizak, H.M., Greene, D.J., Cho, K.H., Paromov, V.M., 2008. Lipid transfer inhibitor protein (apolipoprotein F) concentration in normolipidemic and hyperlipidemic subjects. J. Lipid Res. 49, 127-135.

Nguyen, K.H., Brayer, J., Cha, S., Diggs, S., Yasunari, U., Hilal, G., Peck, A.B., Humphreys-Beher, M.G., 2000. Evidence for antimuscarinic acetylcholine receptor antibody-mediated secretory dysfunction in nod mice. Arthritis Rheum. 43, 2297-2306.

Nguyen, C., Singson, E., Kim, J.Y., Cornelius, J.G., Attia, R., Doyle, M.E., Bulosan, M., Cha, S., Peck, A.B., 2006. Sjogren's syndrome-like disease of C57BL/6.NOD-Aec1 Aec2 mice: gender differences in keratoconjunctivitis sicca defined by a crossover in the chromosome 3 Aec1 locus. Scand. J. Immunol. 64, 295-307.

Nishide, T., Tollefson, J.H., Albers, J.J., 1989. Inhibition of lipid transfer by a unique high density lipoprotein subclass containing an inhibitor protein. J. Lipid Res. 30, 149-158.

Olofsson, S.O., Mcconathy, W.J., Alaupovic, P., 1978. Isolation and partial characterization of a new acidic apolipoprotein (apolipoprotein F) from high density lipoproteins of human plasma. Biochemistry 17, 1032-1036.

Oram, J.F., 2000. Tangier disease and ABCA1. Biochim Biophys. Acta 1529, 321-330.

Palinski, W., Tangirala, R.K., Miller, E., Young, S.G., Witztum, J.L., 1995. Increased autoantibody titers against epitopes of oxidized LDL in LDL receptor-deficient mice with increased atherosclerosis. Arterioscler Thromb. Vasc. Biol. 15, 1569-1576.
Palinski, W., Horkko, S., Miller, E., Steinbrecher, U.P., Powell, H.C., Curtiss, L.K. Witztum, J.L., 1996. Cloning of monoclonal autoantibodies to epitopes of oxidized lipoproteins from apolipoprotein E-deficient mice. Demonstration of epitopes of oxidized low density lipoprotein in human plasma. J. Clin. Invest 98 , 800-814.

Pender, M.P., Csurhes, P.A., Wolfe, N.P., Hooper, K.D., Good, M.F., Mccombe, P.A., Greer, J.M., 2003. Increased circulating T cell reactivity to GM3 and GQ1b gangliosides in primary progressive multiple sclerosis. J. Clin. Neurosci. 10, 63-66.

Plump, A.S., Smith, J.D., Hayek, T., Aalto-Setala, K., Walsh, A., Verstuyft, J.G. Rubin, E.M., Breslow, J.L., 1992. Severe hypercholesterolemia and atherosclerosis in apolipoprotein E-deficient mice created by homologous recombination in ES cells. Cell 71, 343-353.

Redl, B., 2000. Human tear lipocalin. Biochim Biophys. Acta 1482, 241-248.

Ressot, C., Lassagne, H., Kemeny, J.L., Gachon, A.M., 1998. Tissue expression of tear lipocalin in humans. Adv. Exp. Med. Biol. 438, 69-73.

Robinson, C.P., Yamamoto, H., Peck, A.B., Humphreys-Beher, M.G., 1996. Genetically programmed development of salivary gland abnormalities in the NOD (nonobese diabetic)-scid mouse in the absence of detectable lymphocytic infiltration: a potential trigger for sialoadenitis of NOD mice. Clin. Immunol Immunopathol 79, 50-59.

Robinson, C.P., Yamachika, S., Alford, C.E., Cooper, C., Pichardo, E.L., Shah, N Peck, A.B., Humphreys-Beher, M.G., 1997. Elevated levels of cysteine protease activity in saliva and salivary glands of the nonobese diabetic (NOD) mouse model for Sjogren syndrome. Proc. Natl. Acad. Sci. U S A 94, 5767-5771.

Roselaar, S.E., Daugherty, A., 1998. Apolipoprotein E-deficient mice have impaired innate immune responses to Listeria monocytogenes in vivo. J. Lipid Res. 39 $1740-1743$.

Sadatipour, B.T., Greer, J.M., Pender, M.P., 1998. Increased circulating antiganglioside antibodies in primary and secondary progressive multiple sclerosis. Ann. Neurol. 44, 980-983.

Sébédio, J., Juaneda, P., 1991. Quantitative lipid analyses using the new Iatroscan TLC-FID system. J. Planar Chrom. 4, 35-41.

Shamshiev, A., Donda, A., Carena, I., Mori, L., Kappos, L., De Libero, G., 1999. Self glycolipids as T-cell autoantigens. Eur. J. Immunol. 29, 1667-1675.

Shaw, P.X., Horkko, S., Tsimikas, S., Chang, M.K., Palinski, W., Silverman, G.J., Chen, P.P., Witztum, J.L., 2001. Human-derived anti-oxidized LDL autoantibody blocks uptake of oxidized LDL by macrophages and localizes to atherosclerotic lesions in vivo. Arterioscler Thromb. Vasc. Biol. 21, 1333-1339.

Sullivan, D.A., Allansmith, M.R., 1984. Source of IgA in tears of rats. Immunology 53, 791-799.

Thiagarajan, P., 2001. Atherosclerosis, autoimmunity, and systemic lupus erythematosus. Circulation 104, 1876-1877.

Uhlig, H., Dernick, R., 1989. Monoclonal autoantibodies derived from multiple sclerosis patients and control persons and their reactivities with antigens of the central nervous system. Autoimmunity 5, 87-99.

Vaisar, T., Pennathur, S., Green, P.S., Gharib, S.A., Hoofnagle, A.N., Cheung, M.C. Byun, J., Vuletic, S., Kassim, S., Singh, P., Chea, H., Knopp, R.H., Brunzell, J., Geary, R., Chait, A., Zhao, X.Q., Elkon, K., Marcovina, S., Ridker, P., Oram, J.F., Heinecke, J.W., 2007. Shotgun proteomics implicates protease inhibition and complement activation in the antiinflammatory properties of HDL. J. Clin. Invest 117, 746-756.

Van Blokland, S.C., Versnel, M.A., 2002. Pathogenesis of Sjogren's syndrome: characteristics of different mouse models for autoimmune exocrinopathy. Clin. Immunol. 103, 111-124.

Van Haeringen, N.J., 1981. Clinical biochemistry of tears. Surv. Ophthalmol. 26, 84-96.

Wang, X., Driscoll, D.M., Morton, R.E., 1999. Molecular cloning and expression of lipid transfer inhibitor protein reveals its identity with apolipoprotein F. J. Biol. Chem. 274, 1814-1820.

Wang, Y., Lam, K.S., Kraegen, E.W., Sweeney, G., Zhang, J., Tso, A.W., Chow, W.S. Wat, N.M., Xu, J.Y., Hoo, R.L., Xu, A., 2007. Lipocalin-2 is an inflammatory marker closely associated with obesity, insulin resistance, and hyperglycemia in humans. Clin. Chem. 53, 34-41.

Young, S.G., Fielding, C.J., 1999. The ABCs of cholesterol efflux. Nat. Genet 22, 316-318.

Zhang, S.H., Reddick, R.L., Piedrahita, J.A., Maeda, N., 1992. Spontaneous hypercholesterolemia and arterial lesions in mice lacking apolipoprotein E. Science $258,468-471$.

Zoukhri, D., 2006. Effect of inflammation on lacrimal gland function. Exp. Eye Res. $82,885-898$. 